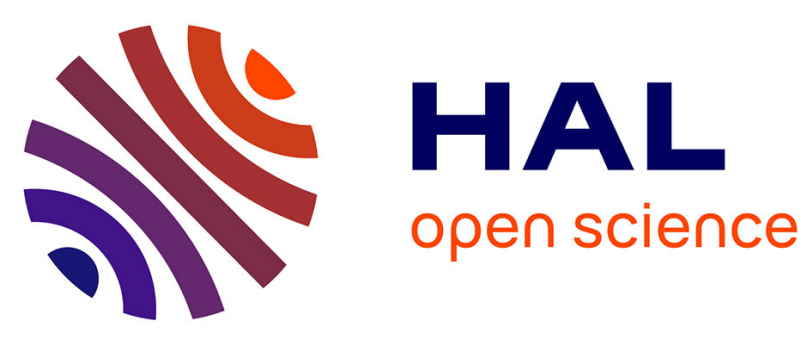

\title{
Polyoxymethylene additives
}

Emmanuel Richaud

\section{To cite this version:}

Emmanuel Richaud. Polyoxymethylene additives. Polyoxymethylene Handbook: Structure, Properties, Applications and Their Nanocomposites, Wiley - Scrivener Publishing, pp.53-105, 2014, 10.1002/9781118914458.ch3 . hal-01199650

\section{HAL Id: hal-01199650 \\ https://hal.science/hal-01199650}

Submitted on 15 Sep 2015

HAL is a multi-disciplinary open access archive for the deposit and dissemination of scientific research documents, whether they are published or not. The documents may come from teaching and research institutions in France or abroad, or from public or private research centers.
L'archive ouverte pluridisciplinaire HAL, est destinée au dépôt et à la diffusion de documents scientifiques de niveau recherche, publiés ou non, émanant des établissements d'enseignement et de recherche français ou étrangers, des laboratoires publics ou privés. 


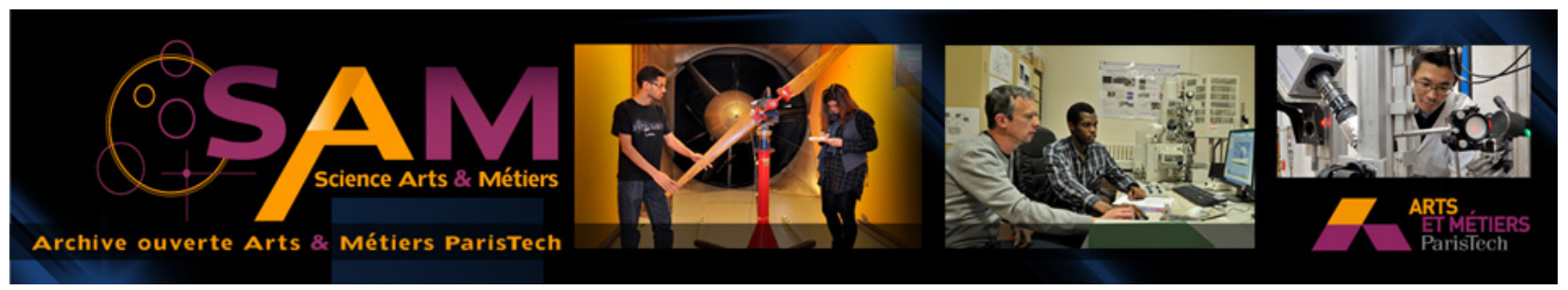

Science Arts \& Métiers (SAM)

is an open access repository that collects the work of Arts et Métiers ParisTech researchers and makes it freely available over the web where possible.

This is an author-deposited version published in: http://sam.ensam.eu

Handle ID: .http://hdl.handle.net/10985/10016

\section{To cite this version :}

Emmanuel RICHAUD - Polyoxymethylene additives - 2014 
E Richaud . Polyoxymethylene Additives. In: "Polyoxymethylene Handbook: Structure, Properties, Applications and Their Nanocomposites”. Sigrid Lüftl, Visakh P.M., Sarath Chandran, editors. 2014. Chap 3, pp 53-105. DOI: 10.1002/9781118914458.ch3

3. Additives

by Dr Emmanuel Richaud

Arts et Metiers ParisTech, CNRS

PIMM, UMR 8006

151 bd de l'Hôpital

75013 PARIS - FRANCE

emmanuel.richaud@ensam.eu

tel : +33144246316

fax : +33144246382

\begin{abstract}
This chapter presents a review of the role of several additives on POM processing (lubricating agents, processing aids, nucleating agents), performances (fillers, impact modifiers) and lifetime increase (antioxidants, compounds reacting with secondary reaction products such as acids scavengers, UV stabilizers and flame retardants) and aspect properties (pigments). It is tried to review existing models permitting to describe the efficiency of these additives in POM and predict the effect of other comparable additives that are not included in this review. Last, since POM compounding can be relatively complex and additives are scarcely used alone, it was also tried to report some side effects of these additives and the possible synergistic or antagonistic effects in the case of combinations of additives.
\end{abstract}

\title{
3.1. Introduction
}

The development of polymers as high diffusion materials was made possible thanks to several sorts of additives that have contributed to their success. These one provide to plastics:

- Stabilization to retain the original molecular architecture of the polymer under the effect heat, light, oxygen etc... causing the chemical unstability of most polymers and subsequent changes of properties expected from material design. In other words, polymer cannot maintain their properties during processing, storage and exposure at device conditions without adding process stabilizers or light antioxidants...

- Functionalization to provide best mechanical, thermal ... properties to the polymer. 
E Richaud . Polyoxymethylene Additives. In: "Polyoxymethylene Handbook: Structure, Properties, Applications and Their Nanocomposites”. Sigrid Lüftl, Visakh P.M., Sarath Chandran, editors. 2014. Chap 3, pp 53-105. DOI: 10.1002/9781118914458.ch3

Not surprisingly, the change in consumption per year of polymers and their additives follow the same trend with a ca 5\% per year growth [1]. This flourishing commercial market has aroused the interest of scientist and engineers that have published a great volume of studies aimed at illustrating the performances of additives in polymers. When browsing this rich literature, two sorts of articles can be distinguished:

- Those showing the properties of additives mixtures for seeking the optimal properties.

- Those focusing on the effect of one additive pure polymer.

This chapter is mostly aimed at reviewing the second sort of research works because they permit to better understand the first ones, and validate the existing predictive models as well. Some mechanisms of polymer degradation are recalled in the 'chemical resistance' chapter of this book so as to present the 'key species' of these mechanisms and which molecules can interact with them.

\subsection{Antioxidants}

\subsubsection{Strategy of stabilization to inhibit thermal oxidation}

There are two main ways for slowing thermal oxidation:

- Decrease the initiation rate, which is the rate of radical generation. For thermal oxidation, this rate is equal to: $\mathrm{r}_{1}=2 \mathrm{k}_{1}[\mathrm{POOH}]^{\delta}$ ( $\delta=1$ or 2 depending on uni- or bimolecular initiation process). For that purpose, hydroperoxides reducers (e.g. phosphites or sulfurs) are added.

- Increase termination rate, i.e. rate at which radical compounds are converted into stable products, using phenolic antioxidants, aromatic amines and Hindered Amine Stabilizers (HAS).

\subsubsection{Case of hydroperoxides reducers in POM}

Hydroperoxides are inherently unstable in POM (see '3.2.3. Thermal Oxidation' section) and decompose essentially by an unimolecular process. From a kinetic point of view, phosphites are thus efficient hydroperoxides reducers typically if: 
E Richaud . Polyoxymethylene Additives. In: "Polyoxymethylene Handbook: Structure, Properties, Applications and Their Nanocomposites". Sigrid Lüftl, Visakh P.M., Sarath Chandran, editors. 2014. Chap 3, pp 53-105. DOI: 10.1002/9781118914458.ch3

$$
\mathrm{r}_{\mathrm{D}}>\mathrm{r}_{1 \mathrm{u}}
$$

i.e.:

$$
\mathrm{k}_{\mathrm{D}}[\mathrm{D}][\mathrm{POOH}]>\mathrm{k}_{\mathrm{u}}[\mathrm{POOH}]
$$

so, using: $\mathrm{k}_{\mathrm{u}}=5.10^{-6} \mathrm{~s}^{-1}, \mathrm{k}_{\mathrm{D}}=10^{-3} 1 \mathrm{~mol}^{-1} \mathrm{~s}^{-1}$ :

$$
[\mathrm{D}]>5.10^{-3} \mathrm{~mol}^{-1} \text { or }[\mathrm{D}]>0.005 \mathrm{~g} / \mathrm{g}
$$

3.2.3. Case of phenolic antioxidants in POM

3.2.3.1. Mechanism of stabilization by antioxidants

Phenolic antioxidants constitute the most common stabilizer family [1]. There is a wide consensus on the nature of the first stabilization event consisting in scavenging $\mathrm{POO}^{\circ}$ radical:

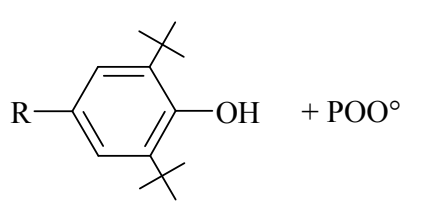

$\mathrm{AH}$

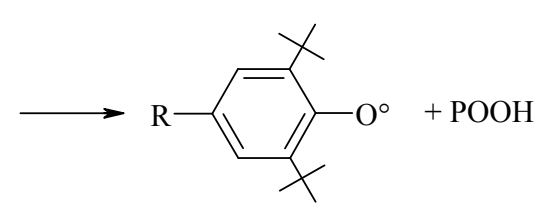

phenoxyl $\left(\mathrm{A}^{\circ}\right)$

Several reactions involving $\mathrm{A}^{\circ}$ are possible [2]. The following scheme could be ascribed:

(Iso) $\quad \mathrm{A}^{\circ} \rightarrow \mathrm{B}^{\circ}$ $\mathrm{k}_{\mathrm{S} 1}$

(S2) $\quad \mathrm{POO}^{\circ}+\mathrm{B}^{\circ} \rightarrow \mathrm{POO}-\mathrm{B}$ $\mathrm{k}_{\text {Iso }}$

(B) $\quad \mathrm{B}^{\circ} \rightarrow$ other reactions $\mathrm{k}_{\mathrm{S} 2}$ $\mathrm{k}_{\mathrm{B}}$

Phenols are irreversibly consumed (contrarily to hindered amine stabilizers presented in the '3.4. UV stabilizers' section) and are hence called 'sacrificial stabilizers'. Some aspects of stabilization by phenolic antioxidants will be illustrated in the next section.

Diphenylamines also belong to the family of sacrificial antioxidants and are mentioned as possible antioxidants for POM [3]. One of their drawbacks is to lead to significant darkening of polymer because of the accumulation of conjugated structures in the polymer:

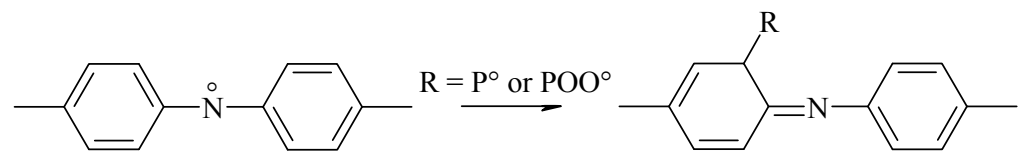


E Richaud . Polyoxymethylene Additives. In: "Polyoxymethylene Handbook: Structure, Properties, Applications and Their Nanocomposites”. Sigrid Lüftl, Visakh P.M., Sarath Chandran, editors. 2014. Chap 3, pp 53-105. DOI: 10.1002/9781118914458.ch3

Carbon black [4] and carbon nanotubes are also expected to have some antioxidant properties, since aromatic nuclei can react with both alkyl and peroxyl radicals:

$\mathrm{P}^{\circ}+\mathrm{Carb} \rightarrow$ inactive product

$\mathrm{POO}^{\circ}+\mathrm{Carb} \rightarrow$ inactive product

Some amine stabilizers can also react with both $\mathrm{P}^{\circ}$ and $\mathrm{POO}^{\circ}$ radicals. They will be presented in the "3.4. UV stabilizers" section.

\subsubsection{Effect of phenol concentration}

During thermo-oxidative aging, stabilizers are continuously consumed as monitored for example by Differential Scanning Calorimetry (DSC) under oxygen [5,6]. When concentration becomes negligible, the oxidation mechanism occurs as in a pure polymer. The stabilizer efficiency can thus be quantified by its ability to delay the induction time of degradation, which is for example the time for losing $10 \%$ of mass. Table 3.1 illustrates the changes of this characteristic time for degradation with stabilizer concentration [7]:

Table 3.1: Time to $10 \%$ mass loss $\left(\mathrm{t}_{10} \%\right)$ in thermal ageing at $140{ }^{\circ} \mathrm{C}$ [7] for POM + phenolic antioxidants with several concentrations.

\begin{tabular}{|c|c|c|c|c|c|c|c|}
\hline $\mathbf{T}$ & AO & $\mathrm{x}(\%)$ & $\mathrm{M}\left(\mathrm{g} \mathrm{mol}^{-1}\right)$ & f & {$[\mathrm{AH}]\left(\mathrm{mol} \mathrm{l}^{-1}\right)$} & $\mathbf{t}_{10 \%}(\mathrm{~min})$ & SE $\left(h \mathrm{l} \mathrm{mol}^{-1}\right)$ \\
\hline \multirow{9}{*}{$140^{\circ} \mathrm{C}$} & AO1 & 0.1 & 574 & 2 & 0.005 & 22 & 74.1 \\
\hline & AO1 & 0.3 & 574 & 2 & 0.015 & 70 & 78.6 \\
\hline & AO1 & 0.5 & 574 & 2 & 0.025 & 95 & 64.0 \\
\hline & AO2 & 0.1 & 638 & 2 & 0.004 & 18 & 67.4 \\
\hline & AO2 & 0.3 & 638 & 2 & 0.013 & 69 & 86.1 \\
\hline & AO2 & 0.5 & 638 & 2 & 0.022 & 90 & 67.4 \\
\hline & AO3 & 0.1 & 340 & 2 & 0.008 & 22 & 43.9 \\
\hline & AO3 & 0.3 & 340 & 2 & 0.025 & 66 & 43.9 \\
\hline & AO3 & 0.5 & 340 & 2 & 0.042 & 78 & 31.1 \\
\hline
\end{tabular}

Stabilizer can be compared by their Stabilizer Efficiency (SE) factor, which could be defined as the increase in characteristic time of degradation per mole of stabilizer initially present in the polymer. Here: 
E Richaud . Polyoxymethylene Additives. In: "Polyoxymethylene Handbook: Structure, Properties, Applications and Their Nanocomposites”. Sigrid Lüftl, Visakh P.M., Sarath Chandran, editors. 2014. Chap 3, pp 53-105. DOI: 10.1002/9781118914458.ch3 $\mathrm{SE} \sim \mathrm{t}_{10 \%} /[\mathrm{AH}]_{0}$

As classically observed [8], SE is decreased when increasing initial stabilizer concentration because a part of stabilizer is certainly lost by evaporative process before having reacted with radicals. The relationship between phenolic stabilizer structure and physical loss will be presented in the next paragraph.

\subsubsection{Effect of phenolic antioxidant structure}

Table 3.2 illustrates the performances of several phenolic antioxidants for retarding degradation induced mass loss:

Table 3.2: Time to 2, 4 or $10 \%$ mass loss for POM with $0.3 \%$ antioxidants $+0.3 \%$ ca stearate from [7,9] together with some characteristics of antioxidants (molar mass and melting temperature).

\begin{tabular}{|c|c|c|c|c|c|c|c|c|c|}
\hline \multicolumn{5}{|c|}{ stabilizer } & \multicolumn{3}{|c|}{$220^{\circ} \mathrm{C}$} & \multicolumn{2}{|c|}{$140^{\circ} \mathrm{C}$} \\
\hline & f & $M\left(\mathrm{~g} \mathrm{~mol}^{-1}\right)$ & $\mathbf{T}_{\mathrm{m}}\left({ }^{\circ} \mathrm{C}\right)$ & {$[\mathrm{AH}]\left(\mathrm{mol} \mathrm{I}^{-1}\right)$} & $t_{2 \%}$ (h) & $t_{10 \%}(h)$ & SE $\left(\mathrm{h} \mathrm{I} \mathrm{mol}{ }^{-1}\right)$ & $\mathbf{t}_{4 \%}$ (h) & $\mathrm{SE}\left(\mathrm{h} \mathrm{I} \mathrm{\textrm {mol } ^ { - 1 } )}\right.$ \\
\hline AO1 & 2 & 586 & $75-79$ & 0.015 & 0.75 & $1.20-1.30$ & $82.5-89.4$ & $3864-4000$ & $(2.66-2.75) \times 10^{5}$ \\
\hline $\mathrm{AO} 2$ & 2 & 638 & $104-108$ & 0.013 & 0.60 & $0.90-1.13$ & $67.4-84.9$ & $2520-2900$ & $(1.89-2.17) \times 10^{5}$ \\
\hline AO3 & 2 & 636 & $156-162$ & 0.013 & 1.08 & $1.75-2.08$ & $130.6-155.5$ & $2500-2772$ & $(1.86-2.07) \times 10^{5}$ \\
\hline AO4 & 4 & 1176 & 125 & 0.014 & 0.55 & $0.87-1.17$ & $59.8-80.5$ & $2772-3000$ & $(1.91-2.07) \times 10^{5}$ \\
\hline AO5 & 2 & 340 & $120-132$ & 0.025 & & 1 & 39.9 & 336 & $0.13 \times 10^{5}$ \\
\hline
\end{tabular}

Table 3.2 calls for the following comments:

(1) At low temperature: $\mathrm{SE}(\mathrm{AO} 1)>\mathrm{SE}(\mathrm{AO} 3), \mathrm{SE}(\mathrm{AO} 2)$ and $\mathrm{SE}(\mathrm{AO} 4)>\mathrm{SE}(\mathrm{AO} 5)$. Solubility is the main physical parameter responsible for stabilizer efficiency at low temperature [10]. In other words, data in table 3.3 would be explained by:

solubility $($ AO5 $)<\operatorname{solubility}($ AO4 $)<\operatorname{solubility(AO2)~}<$ solubility $($ AO3 $)<\operatorname{solubility}($ AO1)

in good agreement with expected structure solubility relationships in a polyether.

(2) At high temperature: $\mathrm{SE}(\mathrm{AO} 3)>\mathrm{SE}(\mathrm{AO} 1), \mathrm{SE}(\mathrm{AO} 2)$ and $\mathrm{SE}(\mathrm{AO} 4)>\mathrm{SE}(\mathrm{AO} 5)$. Stabilizer efficiency is possibly limited by volatile loss. The rate of evaporation was expressed as [11]: 
E Richaud . Polyoxymethylene Additives. In: "Polyoxymethylene Handbook: Structure, Properties, Applications and Their Nanocomposites”. Sigrid Lüftl, Visakh P.M., Sarath Chandran, editors. 2014. Chap 3, pp 53-105. DOI: 10.1002/9781118914458.ch3

$\mathrm{r}_{\text {evap }}=\frac{\mathrm{Vstab}}{[\mathrm{stab}]_{\mathrm{sat}}} \cdot[\mathrm{stab}]$

Assuming that the relative solubility of antioxidants is the same at $220^{\circ} \mathrm{C}$ and $140{ }^{\circ} \mathrm{C}$, data militate in favor of:

volatility $(\mathrm{AO} 3)<$ volatility $(\mathrm{AO} 1)$, volatility $(\mathrm{AO} 4)$ and volatility $(\mathrm{AO} 2)$

in good agreement with the link between the volatility of pure stabilizer $\mathrm{V}_{0}$ (depending on the cohesion in a stabilizer crystal) with its melting temperature $\mathrm{T}_{\mathrm{m}}$ and molar mass .

Another aspect linked to stabilizer structure is illustrated by table 3.3: it seems that stabilizer performances to retain elongation at break (i.e. to inhibit oxidation process) are not linked to their performances to limit discoloration.

Table 3.3: Performances of stabilizer to retain elongation at break and limit color changes $\left(t_{50}\right.$ $=$ time to $50 \%$ of initial elongation at break, $\mathrm{t}_{10}=$ time to discoloration $\Delta \mathrm{E}=10$ )

[12].

\begin{tabular}{|c|c|c|c|c|c|c|c|c|c|}
\hline $\mathbf{T}$ & AO & $\mathbf{x}(\%)$ & I $\left(\mathrm{g} \mathrm{mol}^{-1}\right.$ & $\mathbf{f}$ & [AH] $\left(\mathrm{mol} \mathrm{l}^{-1}\right)$ & $\mathbf{t}_{50 \%}(\mathbf{h})$ & SE $\left(\mathrm{h} \mathrm{I} \mathrm{mol^{-1 } )}\right.$ & $t_{\Delta E=10}(h)$ & $\mathrm{SE}\left(\mathrm{h} 1 \mathrm{~mol}^{-1}\right)$ \\
\hline \multirow{4}{*}{$140^{\circ} \mathrm{C}$} & AO3 & 0.3 & 636 & 2 & 0.013 & 1500 & $1.1 \mathrm{E}+05$ & 150 & $1.1 \mathrm{E}+04$ \\
\hline & AO1 & 0.3 & 574 & 2 & 0.015 & 1500 & $1.0 \mathrm{E}+05$ & 750 & $5.1 \mathrm{E}+04$ \\
\hline & AO6 & 0.3 & 582 & 2 & 0.015 & 2500 & $1.7 \mathrm{E}+05$ & 500 & $3.4 \mathrm{E}+04$ \\
\hline & AO7 & 0.3 & 1090 & 3 & 0.012 & 750 & $6.4 \mathrm{E}+04$ & 250 & $2.1 \mathrm{E}+04$ \\
\hline
\end{tabular}

This is linked to the nature of the reaction product between $\mathrm{POO}^{\circ}$ and $\mathrm{A}^{\circ}$ depending on the nature of 2, 4 and 6 substituent:
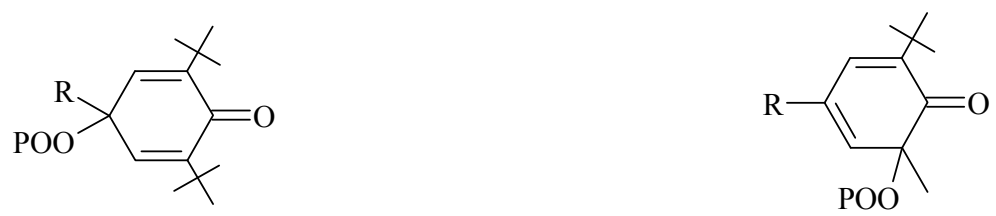

In other words, even if the rate of reaction with $\mathrm{POO}^{\circ}$ is almost the same, these antioxidants have not the same effect on color changes because of the nature of formed products.

\subsubsection{Kinetic parameters for stabilization}


E Richaud . Polyoxymethylene Additives. In: "Polyoxymethylene Handbook: Structure, Properties, Applications and Their Nanocomposites”. Sigrid Lüftl, Visakh P.M., Sarath Chandran, editors. 2014. Chap 3, pp 53-105. DOI: 10.1002/9781118914458.ch3

At moderate temperature, when evaporation plays a negligible role, SE is very close for all stabilizers under study. This militates in favor of a very close $\mathrm{k}_{\mathrm{S} 1}$ value for all the members of the hindered phenol family, as suggested by Gur'yanova et al. [13] who calculated a rate constants ratio characterizing the stabilizer efficiency $\mathrm{k}_{\mathrm{S} 1}{ }^{2} / \mathrm{k}_{6}$. It seemed to us interesting to compare $\mathrm{k}_{\mathrm{S} 1}$ with $\mathrm{k}_{3}$, having in mind that:

$$
\begin{array}{ll}
\mathrm{POO}^{\circ}+\mathrm{AH} \rightarrow \mathrm{POOH}+\mathrm{A}^{\circ} & \mathrm{k}_{\mathrm{S} 1} \\
\mathrm{POO}^{\circ}+\mathrm{PH} \rightarrow \mathrm{POOH}+\mathrm{P}^{\circ} & \mathrm{k}_{3}
\end{array}
$$

are in competition. Estimated values are gathered in table 3.4.

Table 3.4: $\mathrm{k}_{\mathrm{S} 1}$ and $\mathrm{k}_{3} / \mathrm{k}_{\mathrm{S} 1}$ at $60^{\circ} \mathrm{C}$ from the $\mathrm{k}_{\mathrm{S} 1} / \mathrm{k}_{6}$ value by [13] and $\mathrm{k}_{3}$ and $\mathrm{k}_{6}$ from [14].

\begin{tabular}{ccccccc}
\hline & AO3 & AO8 & AO9 & AO10 & AO11 & AO12 \\
\hline $\mathbf{k}_{\mathbf{S 1}} / \mathbf{k}_{\mathbf{6}}{ }^{\mathbf{1}}$ & 3.2 & 2.5 & 0.6 & 5.3 & 4.5 & 8.53 \\
$\mathbf{k}_{\mathbf{6}}$ & \multicolumn{6}{c}{$3.6 \mathrm{E}+04$} \\
$\mathbf{k}_{\mathbf{3}}$ & \multicolumn{6}{c}{$5.9 \mathrm{E}-03$} \\
$\mathbf{k}_{\mathbf{S} 1}$ & $6.0 \mathrm{E}+02$ & $4.7 \mathrm{E}+02$ & $1.1 \mathrm{E}+02$ & $1.0 \mathrm{E}+03$ & $8.5 \mathrm{E}+02$ & $1.6 \mathrm{E}+03$ \\
$\mathbf{k}_{\mathbf{S} \mathbf{1}} / \mathbf{k}_{\mathbf{3}}$ & $1.0 \mathrm{E}+05$ & $8.0 \mathrm{E}+04$ & $1.9 \mathrm{E}+04$ & $1.7 \mathrm{E}+05$ & $1.4 \mathrm{E}+05$ & $2.7 \mathrm{E}+05$ \\
\hline
\end{tabular}

The fact that kinetic parameters are very close for all these phenolic antioxidants could be explained by the fact that they react by giving a hydrogen to $\mathrm{POO}^{\circ}$ radical as observed in other polymers [15]. The corresponding $\mathrm{k}_{\mathrm{S} 1}$ rate constant value is thus linked to $\mathrm{BDE}(\mathrm{O}-\mathrm{H})$ in phenol and is almost independent of ortho, meta, para substituent nature.

As it will be seen later, some interactions exist with fillers, pigments and ultra violet radiation (UV) stabilizers.

\subsection{Compounds reacting with secondary reaction products}

To prevent further acidolysis (see 'Chapter 11 - Chemical properties'), polyacetals and copolymers are protected by co-stabilizers being acid acceptors that react with formaldehyde to yield inert products. Suitable co-stabilizers are polyhydroxy compounds, melamineformaldehyde condensation products [16], urea and its derivatives, amide and polyamides 
E Richaud . Polyoxymethylene Additives. In: "Polyoxymethylene Handbook: Structure, Properties, Applications and Their Nanocomposites". Sigrid Lüftl, Visakh P.M., Sarath Chandran, editors. 2014. Chap 3, pp 53-105. DOI: 10.1002/9781118914458.ch3 $[16,17,18,19]$ and salts of carboxylic acids (also expected to ease processing - see "3.10. Lubricating agents"). Some other molecules enhancing also thermal stability under nonoxidative condition such as POSS [20] possibly also belong to this family.

\subsection{UV stabilization}

\subsubsection{Generality on UV stabilization}

Let us describe the main effect of photo-oxidation as follows:

$\mathrm{X}+\mathrm{h} v \rightarrow \mathrm{P}^{\circ} \quad \mathrm{k}_{\mathrm{uP}}$

$\mathrm{X}$ being a chromophor of which direct photochemistry is a supplementary source of radical destabilizing the polymer. The aim is to decrease the rate constant $\mathrm{k}_{\mathrm{uP}}$ for photochemically induced imitation. Polymers can be UV stabilized:

(1) by a mineral coating working as an UV shield [21]. This was not tried in the case of POM to our knowledge.

(2) by adding pigments, such as carbon black, decreasing the penetration of UV in polymers,

(3) by adding chemicals in the bulk, of which properties are:

- a high molar absorptivity in the solar UV range (typically higher than $10^{4} 1 . \mathrm{mol}^{-1} . \mathrm{s}^{-1}$ in $300 \mathrm{~nm}$ to $400 \mathrm{~nm}$ wavelength range) which permits to absorb radiations even at low concentration (typically $0.001 \mathrm{~g} / \mathrm{g}$ to $0.01 \mathrm{~g} / \mathrm{g}$ ).

- the ability to dissipate energy coming from UV light into heat without yielding radicals which is linked to the formation of isomers involving an intramolecular hydrogen bond as for example the case of hydroxybenzophenones:<smiles>O=C1C=CC(=C(O)c2ccccc2)C(Oc2ccccc2)=C1</smiles>

Hydroxybenzotriazoles $[22,23]$ and triazines are other current UV stabilizers: 
E Richaud . Polyoxymethylene Additives. In: "Polyoxymethylene Handbook: Structure, Properties, Applications and Their Nanocomposites”. Sigrid Lüftl, Visakh P.M., Sarath Chandran, editors. 2014. Chap 3, pp 53-105. DOI: 10.1002/9781118914458.ch3<smiles>[R]c1ccc2nn(-c3ccccc3O)nc2c1</smiles>

hydroxybenzotriazole

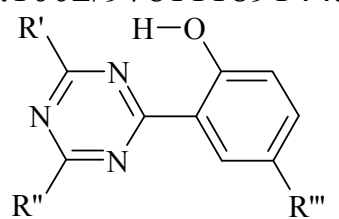

triazine

The performances of these molecules are compared in table 3.5 [24]:

Table 3.5: Typical lifetime (time for retaining $40 \%$ elongation) of POM samples with various photostabilizers submitted to Xenotest 450 (29 min light, 1 min water spraying) or natural ageing (Frankfurt, Germany, $45^{\circ}$ facing South).

\begin{tabular}{ccc}
\hline & artificial ageing & natural ageing \\
\hline without & 0 & 5 \\
$1.5 \%$ hydroxybenzophenone & 850 & 12 \\
1.0 hydroxybenzotriazole & $>1000(65 \%)$ & 18 \\
$0.5 \%$ carbon black & $>1000(85 \%)$ & $>36$ \\
\hline
\end{tabular}

Typical structures of UV absorbers are shown above. The nature of R- controls some key physical properties such as migration and physical loss. Wu et al [25] compared the stabilization by 2,4 dihydroxybenzophenone in the case of:

- grafting on an oligomer:

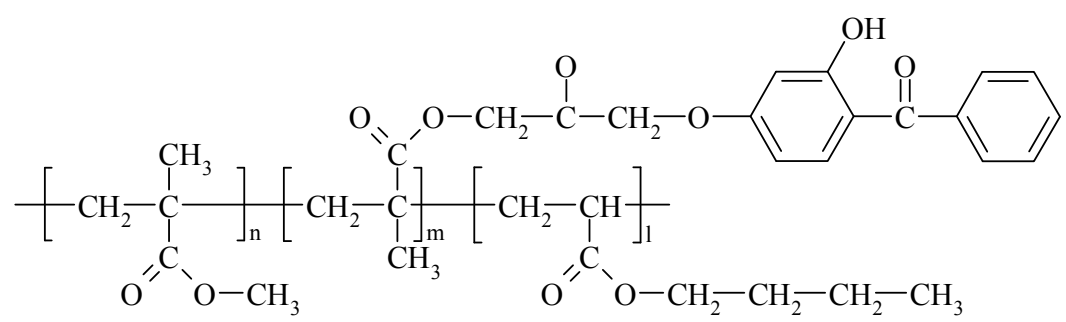

- simple mixing with the polymer matrix.

Their result showed a certain improvement in retaining mechanical properties when UV absorber is grafted instead of mixed, thus highlighting the already mentioned importance of volatility on stabilizer performances. They also showed that the UV stabilization could be improved if UV absorber was hold by a core-shell polymer instead of a copolymer [26].

(4) by adding chain breaking antioxidants such as Hindered Amine Stabilizers [24] that are molecules containing the 2,2,6,6 methyl piperidine group: 
E Richaud . Polyoxymethylene Additives. In: "Polyoxymethylene Handbook: Structure, Properties, Applications and Their Nanocomposites". Sigrid Lüftl, Visakh P.M., Sarath Chandran, editors. 2014. Chap 3, pp 53-105. DOI: 10.1002/9781118914458.ch3

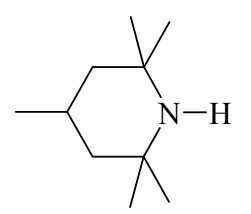

They have aroused a huge quantity of research work after which, even if the stabilization mechanism remains no totally elucidated, the following facts are widely accepted:

- $>\mathrm{NH}$ is converted into $>\mathrm{N}-\mathrm{O}^{\circ}$ radicals play a key role,

$->\mathrm{N}-\mathrm{O}^{\circ}$ is converted into alkoxyamine $>\mathrm{N}-\mathrm{O}-\mathrm{P}$ or hydroxylamine $>\mathrm{N}-\mathrm{O}-\mathrm{H}$ able to trap $\mathrm{POO}^{\circ}$ radicals and regenerating $>\mathrm{N}-\mathrm{O}^{\circ}[27]$ :

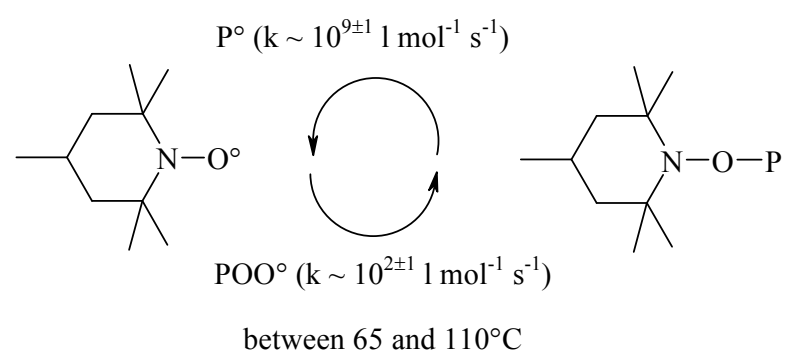

Let us emphasize that they are also expected to be efficient thermal antioxidants, even if Hindered Amine Light Stabilizer (HALS) efficiency is more often in conditions of light induced ageing than in thermal oxidation. Their stabilizing efficiency is thus due to the fact that they trap both $\mathrm{P}^{\circ}$ and $\mathrm{POO}^{\circ}$, and that stabilizing forms $\left(>\mathrm{N}-\mathrm{O}^{\circ},>\mathrm{N}-\mathrm{O}-\mathrm{P}\right.$ or $\left.>\mathrm{N}-\mathrm{O}-\mathrm{H}\right)$ are regenerated contrarily to phenols, phosphites or sulfurs. According to Sedlár̆ and Zahradničková, HALS stabilization can be divided into four steps [28] (Fig. 3.1): 
E Richaud . Polyoxymethylene Additives. In: "Polyoxymethylene Handbook: Structure, Properties, Applications and Their Nanocomposites”. Sigrid Lüftl, Visakh P.M., Sarath Chandran, editors. 2014. Chap 3, pp 53-105. DOI: 10.1002/9781118914458.ch3

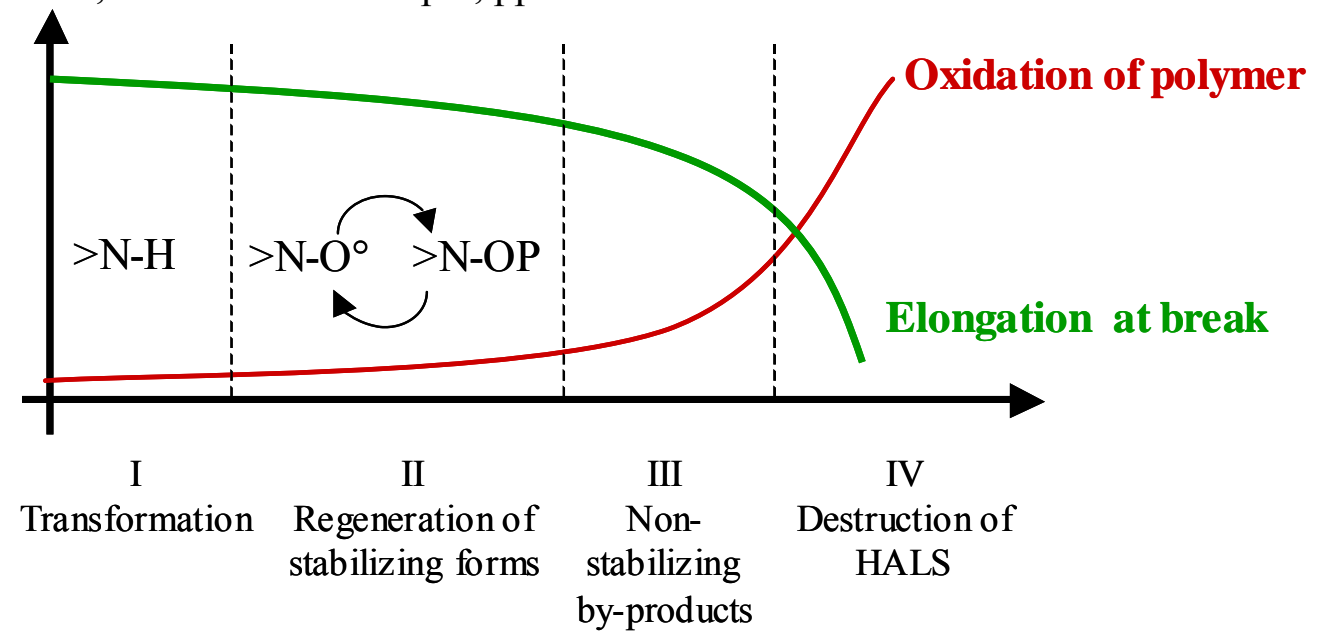

Figure 3.1: Stabilization by HALS.

- Phase I: amine reaction into $>\mathrm{N}-\mathrm{O}^{\circ}$ radical.

- Phase II: regenerative cycle $>\mathrm{N}-\mathrm{O}^{\circ} \leftrightarrows>\mathrm{N}-\mathrm{O}-\mathrm{P}$ or $>-\mathrm{N}-\mathrm{O}-\mathrm{H}$.

- Phase III: irreversible conversion of stabilizing forms into non stabilizing ones.

- Phase IV: total consumption of stabilizing forms and polymer oxidation and stabilization.

\subsubsection{Performances of UV stabilizers in POM}

Performances of several HALS and UV absorbers are reported in tables 3.6, 3.7 and 3.8 [38] for various accelerated ageing conditions.

Table 3.6: Time to chalking and corresponding SE factor for POM + stabilizer (Base stabilization: $0.3 \%$ stearate $+0.3 \%$ AO 2) submitted to Xenotest 1200 with black panel temperature equal to $53^{\circ} \mathrm{C}$ without water spraying. For HALS, $\mathrm{M}$ is the molar mass of repetitive unit of oligomeric stabilizer.

\begin{tabular}{|c|c|c|c|c|c|}
\hline stabilizer & $\mathbf{m} / \mathbf{m}$ & $\mathrm{M}\left(\mathrm{g} \mathrm{mol}^{-1}\right)$ & $\mathrm{c}\left(\mathrm{mol} \mathrm{l}^{-1}\right)$ & time to chalking (h) & $\mathrm{SE}\left(\mathrm{h} \mathrm{I} \mathrm{\textrm {mol } ^ { - 1 } )}\right.$ \\
\hline- & 0 & - & 0 & 1400 & $0.00 \mathrm{E}+00$ \\
\hline UVA 1 & $0.25 \%$ & 225 & 0.016 & 4000 & $1.65 \mathrm{E}+05$ \\
\hline UVA 1 & $0.50 \%$ & 225 & 0.032 & 5000 & $1.14 \mathrm{E}+05$ \\
\hline UVA 2 & $0.25 \%$ & 351 & 0.010 & 3800 & $2.37 \mathrm{E}+05$ \\
\hline UVA 3 & $0.25 \%$ & 323 & 0.011 & 3800 & $2.18 \mathrm{E}+05$ \\
\hline HALS 1 & $0.25 \%$ & 277 & 0.013 & 3200 & $1.40 \mathrm{E}+05$ \\
\hline HALS 1 & $0.50 \%$ & 277 & 0.026 & 3200 & $7.02 \mathrm{E}+04$ \\
\hline HALS 2 & $0.25 \%$ & 299 & 0.012 & 3600 & $1.85 \mathrm{E}+05$ \\
\hline HALS 2 & $0.50 \%$ & 299 & 0.024 & 4000 & $1.09 \mathrm{E}+05$ \\
\hline
\end{tabular}


E Richaud . Polyoxymethylene Additives. In: "Polyoxymethylene Handbook: Structure, Properties, Applications and Their Nanocomposites”. Sigrid Lüftl, Visakh P.M., Sarath Chandran, editors. 2014. Chap 3, pp 53-105. DOI: 10.1002/9781118914458.ch3

Table 3.7: Time to crack of POM + several UV + HALS mixtures (base stabilization $0.1 \%$ Ca stearate $+0.1 \%$ Melamine $+0.15 \%$ AO 1) submitted to $0.55 \mathrm{~W} \mathrm{~m}^{-2}$ at $340 \mathrm{~nm}$ irradiation.

\begin{tabular}{ccccc}
\hline stabilizer & Y.I. (t = 0) & Y.I. (t = 896h) & \% gloss loss & time to crack (h) \\
\hline without & 4.0 & $0.6(320 \mathrm{~h})$ & $89.3(384 \mathrm{~h})$ & 120 \\
0.3\% UVA 4 + 0.3\% HALS 1 & 9.3 & 8.8 & 27.4 & 384 \\
0.6\% UVA 4 + 0.6\% HALS 1 & 12.7 & 11.0 & 21.0 & 512 \\
0.3\% UVA 4 + 0.3\% HALS 3 & 6.0 & 10.3 & 63.5 & 384 \\
0.6\% UVA 4 + 0.6\% HALS 3 & 7.8 & 15.2 & 47.5 & 448 \\
0.3\% UVA 4 + 0.3\% HALS 4 & 8.9 & 8.5 & 32.9 & 384 \\
0.6\% UVA 4 + 0.6\% HALS 4 & 12.0 & 11.0 & 20.5 & 384 \\
0.3\% UVA 4 + 0.3\% HALS 5 & 7.5 & 7.6 & 25.9 & 384 \\
0.6\% UVA 4 + 0.6\% HALS 5 & 9.9 & 9.8 & 21.5 & 448 \\
\hline
\end{tabular}

Table 3.8: Initial Yellow index, yellow index after ageing, relative gloss loss and estimated energy received to crack for stabilized POM samples (base stabilization: $0.1 \% \mathrm{Ca}$ stearate $+0.15 \%$ AO1) submitted to natural exposure (Florida $-45^{\circ} \mathrm{C}$ South direct).

\begin{tabular}{ccccc}
\hline stabilizer & Y.I. (t = 0) & Y.I. & \% gloss loss & Energy recieved to crack (h) \\
\hline without & 2.9 & 5.5 & 28.4 & 85 \\
0.4\% HALS 1 & 2.6 & 3.5 & 36.2 & 165 \\
0.3\% UVA 4 & 5.3 & 6.0 & 25.0 & 165 \\
$0.3 \%$ UVA 4 + 0.4\% HALS 1 & 5.7 & 5.9 & 25.0 & 250 \\
\hline
\end{tabular}

Identically to phenolic antioxidants (see '3.2. Antioxidants' section), a SE value was determined in the case of simple polymer + stabilizers binary mixtures, showing that:

- Stabilizers efficiency seems to increase with molar mass, possibly because of stabilizer volatile loss.

- The SE decrease when increasing the stabilizer concentration can be due to physical limits of stabilization as for example a greater concentration than solubility limit.

- Changes in aspect properties (yellow index, gloss loss) are difficult to interpret.

Possible negative interaction may occur with fillers [29] due to adsorption at the surface of filler. Antagonisms were also reported with halogenated flame retardants [30]. HALS are quite basic. They can hence react with acidic groups to form an inactive salt: 
E Richaud . Polyoxymethylene Additives. In: "Polyoxymethylene Handbook: Structure, Properties, Applications and Their Nanocomposites". Sigrid Lüftl, Visakh P.M., Sarath Chandran, editors. 2014. Chap 3, pp 53-105. DOI: 10.1002/9781118914458.ch3

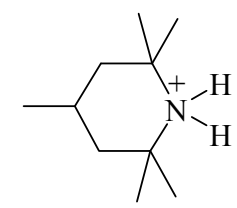

This problem can be avoided by replacing HALS with $>\mathrm{N}-\mathrm{H}$ group $\left(\mathrm{pK}_{\mathrm{B}}=4.3-7.4\right)$ by HALS with $>$ N-R (5.5-8.5) or $>$ N-OR (9.8-10.0) [31] groups.

Last, let us mention that phenols may react with HALS by antagonistic mechanisms:

- abstraction of $\mathrm{H}$ by $\mathrm{NO}^{\circ}[32,33]$ :

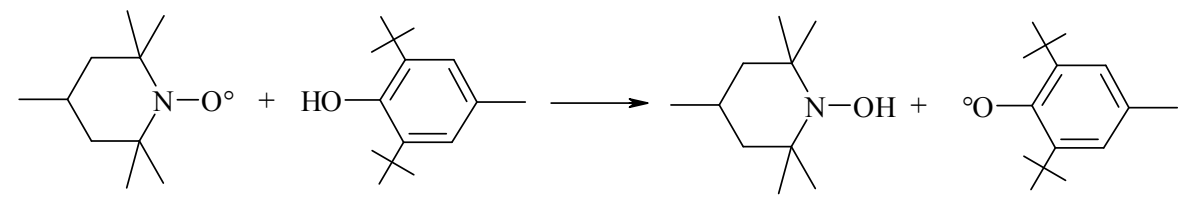

- reaction between nitroxy and phenoxy leading to unstabilizing products [34]:

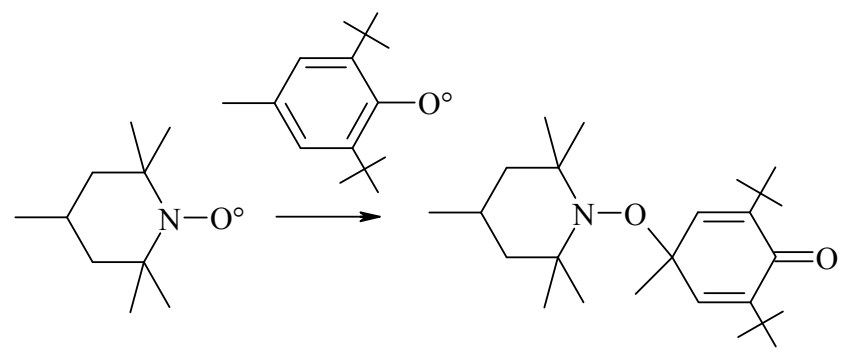

\subsection{Impact modifier}

Impact strength of a polymer is increased with temperature, broadness of molar mass distribution, and decreases with crystalline phase content and crystal size [35]. POM is a rigid and semi-crystalline polymer characterized by tough behavior but is notch sensitive, with a good resistance to crack initiation, but a poor resistance to crack propagation. Its impact strength can be improved by incorporating a rubber phase dispersed in the rigid matrix acting as a stress concentrator and forming a barrier to the extension of crazing.

Starting from a theory proposed by Wu [36], Kanai et al [37] showed that:

- Interparticle distance has a greater influence of on impact modification than particle size.

- Impact strength increase when average interparticle distance is below a critical value.

- The lower interparticle value is, the lower the brittle-tough temperature is. 
E Richaud . Polyoxymethylene Additives. In: "Polyoxymethylene Handbook: Structure, Properties, Applications and Their Nanocomposites”. Sigrid Lüftl, Visakh P.M., Sarath Chandran, editors. 2014. Chap 3, pp 53-105. DOI: 10.1002/9781118914458.ch3

The performances of several additives to increase impact resistance are illustrated in figure 3.2 .

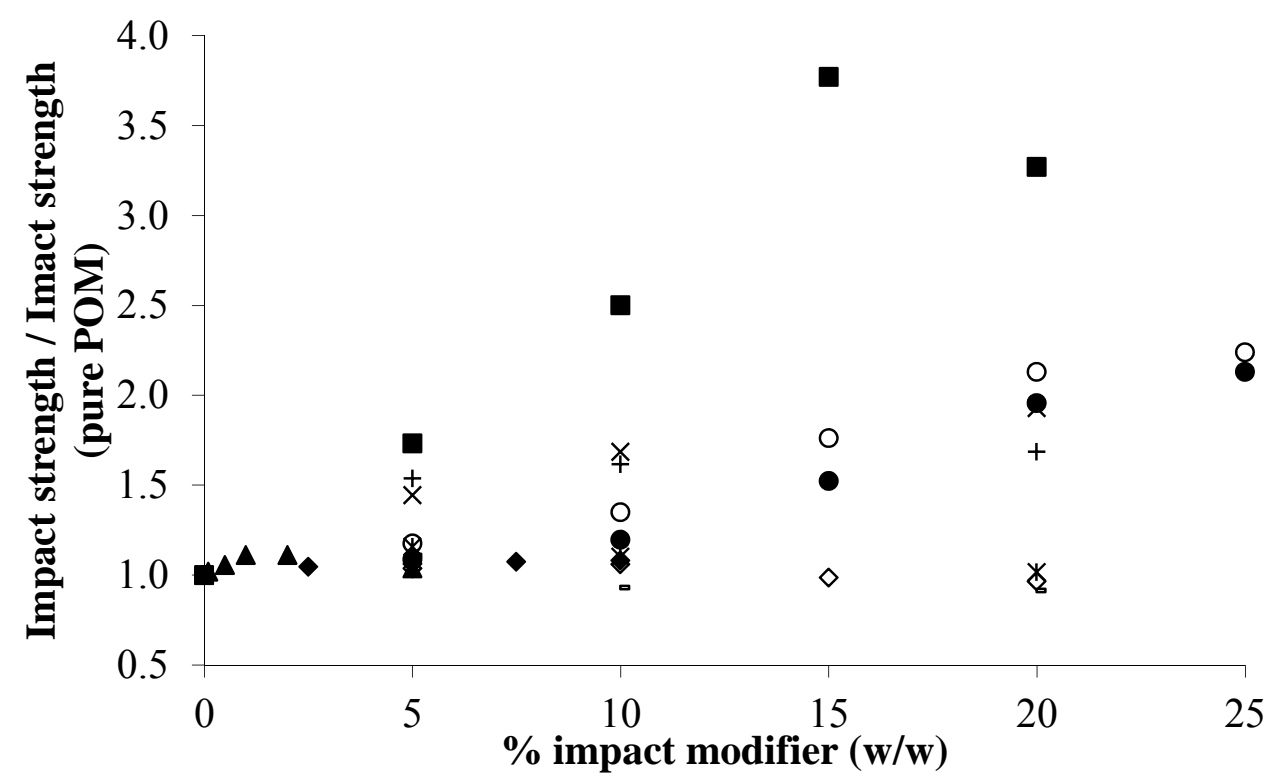

Figure 3.2: Changes of relative impact strength with impact modifier mass fraction: terpolymer of ethylene, metacrylate and acrylic acid (EAAT) (-), EAAT with $25 \%$ of $\mathrm{COOH}$ neutralized with zinc acetate $(\times)$, EAAT with $50 \%$ of $\mathrm{COOH}$ neutralized with zinc acetate $(+)$, EAAT with $100 \%$ of $\mathrm{COOH}$ neutralized with zinc acetate $(*)$ [38], Ethylene methacrylic acid (EMA) with $5.35 \% \mathrm{~m} / \mathrm{m} \mathrm{Zn}$ (O), EMA with $7.18 \% \mathrm{Na}(\bigcirc)$ [39], Multiwall carbon nanotubes (MWCNT) (A) [40], thermoplastic polyurethane (PUR) (ם) [41], Ethylene Diene Rubber $(\mathrm{EPDM})(\diamond)$ and EPDM grafted with maleic anhydride $(\diamond)[42]$.

These results show that the linear relationship proposed by Hashemi et al [43]: $\mathrm{K}_{\mathrm{c}, \text { POM/filler }}=$ $\mathrm{K}_{\mathrm{c}, \text { POM. }}\left(1+\mathrm{k} . \Phi_{\text {filler }}\right)$ seems to be almost verified for a wide range of fillers.

Ionomers such as $\mathrm{Na}$ or $\mathrm{Zn}$ salts of ethylene-methacrylic acid copolymers are reported to be impact modified of POM and its blends [53]:<smiles>CCCC(CCCCCCCC(CC)C(=O)O)CCCCCC(CCC)C(=O)O</smiles> 
E Richaud . Polyoxymethylene Additives. In: "Polyoxymethylene Handbook: Structure, Properties, Applications and Their Nanocomposites”. Sigrid Lüftl, Visakh P.M., Sarath Chandran, editors. 2014. Chap 3, pp 53-105. DOI: 10.1002/9781118914458.ch3

Their reinforcement properties decrease when neutralizing carboxylate groups to form carboxylic acids because of the loss of intermolecular bonds $-\mathrm{COO}^{-}:: \mathrm{M}^{\mathrm{n+}}:: \mathrm{C}^{-} \mathrm{OOC}-$.

PUR is often mentioned in literature and is a reliable solution for POM toughening [35,41,44]. Mehrabzadeh [44] showed that the toughening was improved when polyurethane was crosslinked instead of linear. In the case of EPDM, a slight improvement was observed when EPDM was grafted with maleic anhydride, which acts as a compatibilizer [56].

Last, the impact strength improvement is counterbalanced by negative effect of impact modifiers on modulus changes (Fig. 3.3).

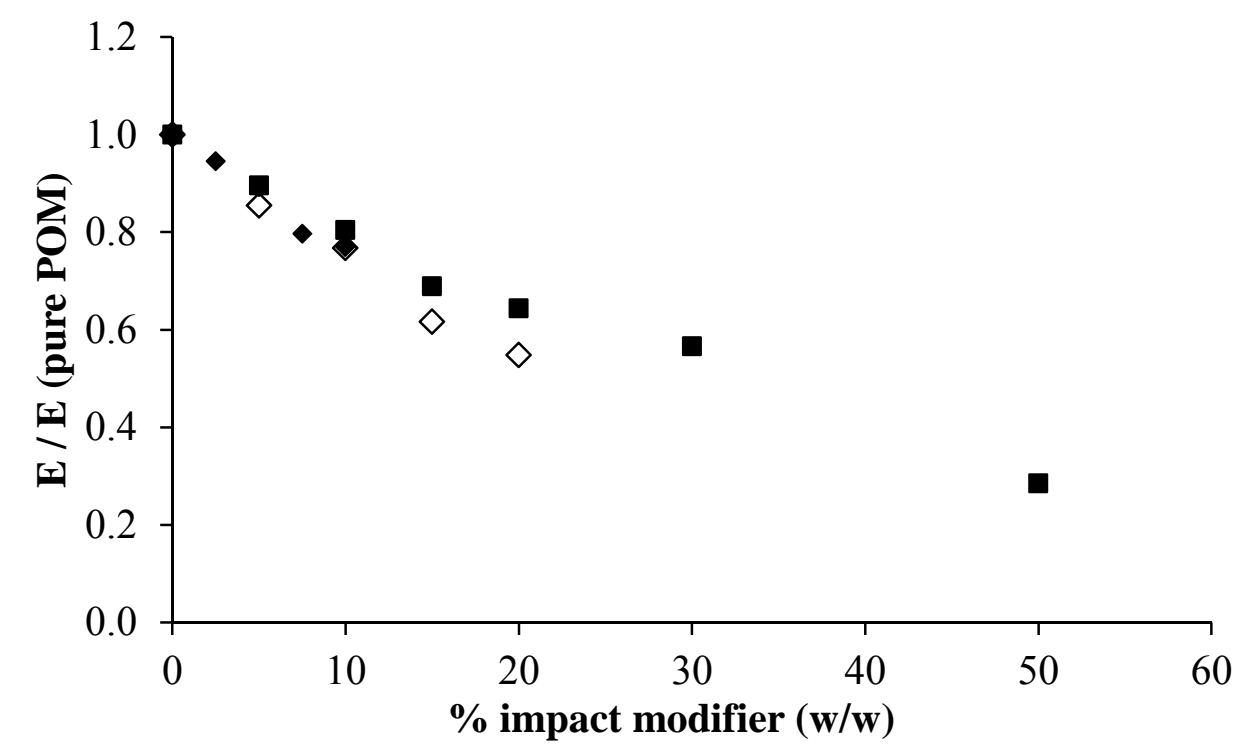

Figure 3.3: Changes of relative Young modulus with impact modifier mass fraction: thermoplastic polyurethane $(\mathbf{\square})[41], \operatorname{EPDM}(\diamond)$ and EPDM grafted with maleic anhydride $(\diamond)[42]$.

\subsection{Nucleating agent}

3.6.1. Theoretical recall on crystallization of polymers

The crystallization is the consequences of two phenomena: the nucleation and then the crystal growth. Nucleation can be:

(1) spontaneous,

(2) orientation induced, 
E Richaud . Polyoxymethylene Additives. In: "Polyoxymethylene Handbook: Structure, Properties, Applications and Their Nanocomposites". Sigrid Lüftl, Visakh P.M., Sarath Chandran, editors. 2014. Chap 3, pp 53-105. DOI: 10.1002/9781118914458.ch3

(3) heterogeneous i.e. occurring at the interface of an extrinsic media on which chains align thus favoring crystallization. This is the case when nucleating agents are added. Let us recall some general features of these compounds:

- they contain both an organic group and a polar group,

- they are well dispersed in the polymer,

- they are insoluble,

- they have a common periodicity with the polymer crystal.

The polymer crystal itself can be thus considered as the ideal nucleating agent. The efficiency of a nucleating agent can be estimated from three distinct characteristics [45]:

(1) The Avrami constants expressing the progress of isothermal crystallization:

- In isothermal conditions:

The time to reach $50 \%$ crystallization being equal to:

- In non-isothermal conditions:

$$
\begin{aligned}
& \mathrm{x}_{\mathrm{C}}=1-\exp \left(-\mathrm{k} \cdot \mathrm{t}^{\mathrm{n}}\right) \\
& \mathrm{t}_{1 / 2}=\left[\frac{\ln 2}{\mathrm{k}}\right]^{1 / \mathrm{n}}
\end{aligned}
$$

$$
\begin{array}{r}
\mathrm{x}_{\mathrm{C}}=1-\exp \left(-\mathrm{Z}_{\left.\mathrm{t} \cdot \mathrm{t}^{\mathrm{n}}\right)}\right. \\
\ln \mathrm{Z}_{\mathrm{C}}=\frac{\ln \mathrm{Z}_{\mathrm{t}}}{\Phi}
\end{array}
$$

$\mathrm{Z}_{\mathrm{t}}$ being the rate of non-isothermal crystallization and $\Phi$ the temperature ramps value and $n$ the Avrami exponent, depending on the mechanism and the geometry of crystal growth.

(2) The crystallization temperature from molten state (corresponding to peak temperature measured in DSC), which can be exploited to calculate the nucleating efficiency:

$$
\mathrm{NE}=\frac{\mathrm{T}_{\mathrm{C}, \mathrm{NA}}-\mathrm{T}_{\mathrm{C} 1}}{\mathrm{~T}_{\mathrm{C} 2, \max }-\mathrm{T}_{\mathrm{Cl}}} \times 100
$$

Where:

- $\mathrm{T}_{\mathrm{C}, \mathrm{NA}}$ is the peak temperature for the polymer crystallization in presence of nucleating agent.

- $\mathrm{T}_{\mathrm{Cl}}$ is the peak temperature for the pure polymer crystallization.

- $\mathrm{T}_{\mathrm{C} 2 \text {,max }}$ is the peak temperature for the self-nucleated polymer crystallization. 
E Richaud . Polyoxymethylene Additives. In: "Polyoxymethylene Handbook: Structure, Properties, Applications and Their Nanocomposites". Sigrid Lüftl, Visakh P.M., Sarath Chandran, editors. 2014. Chap 3, pp 53-105. DOI: 10.1002/9781118914458.ch3

(3) The crystalline ratio and the thickness of crystalline lamellae, which is linked to the melting temperature by the Gibbs Thompson equation:

$$
\begin{aligned}
& \mathrm{x}_{\mathrm{C}}=\frac{\Delta \mathrm{H}_{\mathrm{m}}}{\Delta \mathrm{H}_{\mathrm{m} 100}} \\
& \mathrm{l}_{\mathrm{C}}=\frac{2 \gamma_{\mathrm{E}}}{\Delta \mathrm{H}_{\mathrm{m} 100}} \cdot\left(1-\frac{\mathrm{T}_{\mathrm{m}}}{\mathrm{T}_{\mathrm{m} 100}}\right)^{-1}
\end{aligned}
$$

where :

$-\gamma_{\mathrm{E}}$ is the surface tension at the lamellae-amorphous phase interface equal to $0.125 \mathrm{~J} \mathrm{~m}^{-2}$ [46].

- $\Delta \mathrm{H}_{\mathrm{m}}$ and $\mathrm{T}_{\mathrm{m}}$ are respectively melting enthalpy and melting temperature of polymer.

- $\Delta \mathrm{H}_{\mathrm{m} 100}$ and $\mathrm{T}_{\mathrm{m} 100}$ are respectively melting enthalpy and melting temperature for a fictive $100 \%$ crystalline polymer equal to $380.10^{6} \mathrm{~J} \mathrm{~m}^{-3}$ [46].

\subsubsection{Effect of some nucleating agents in POM}

Nucleating agents are efficient when polymer has an intermediary crystallization rate that can be easily increased. On the contrary, they are unnecessary if the polymer crystallizes spontaneously very fast (for example HDPE), or extremely slow (for example polycarbonate). It seemed to us interesting to compare the crystallization kinetics of POM with other semicrystalline thermoplastics (table 3.9):

Table 3.9: Avrami's parameters and corresponding half time for maximal crystallization of some thermoplastics $[47,48,49]$.

\begin{tabular}{cccccc}
\hline$\Phi\left({ }^{\circ} \mathbf{C} \mathbf{~ m i n}^{-1}\right)$ & polymer & $\mathbf{n}$ & $\mathbf{Z}_{\mathbf{C}}$ & $\mathbf{Z}_{\mathbf{t}}$ & $\mathbf{t}_{\mathbf{1 / 2}}$ (min) \\
\hline \multirow{3}{*}{5} & PP & 4.8 & 0.54 & 0.05 & 1.75 \\
& PE & 2.3 & 1.44 & 6.19 & 0.39 \\
& POM & 4.89 & 0.67 & 0.14 & 1.40 \\
\hline \multirow{2}{*}{10} & PP & 4.3 & 0.96 & 0.67 & 1.01 \\
& PE & 2.2 & 1.28 & 11.81 & 0.28 \\
& POM & 4.31 & 1.06 & 1.79 & 0.80 \\
\hline
\end{tabular}

Table 3.9 suggests that the improvement in crystallization rate will not be as striking as it is for example in polypropylene (PP). The effect of several nucleating agents or additives can be appreciated by a short compilation of experimental results comparing the above-presented characteristics for POM and POM with additives (Tables 3.10, 3.11, 3.12 and 3.13). 
E Richaud . Polyoxymethylene Additives. In: "Polyoxymethylene Handbook: Structure, Properties, Applications and Their Nanocomposites”. Sigrid Lüftl, Visakh P.M., Sarath Chandran, editors. 2014. Chap 3, pp 53-105. DOI: 10.1002/9781118914458.ch3

Table 3.10: Effect of hydroxyappatite (HAP) on POM crystallization from molten state from DSC measurements. $\mathrm{T}_{\text {onset }}=$ temperature of crystallization start, $\mathrm{T}_{\max }=$ temperature of maximal energy release, and $\mathrm{T}_{\text {end }}=$ temperature of end of transition.

\begin{tabular}{cccc}
\hline & $\mathbf{T}_{\text {onset }}\left({ }^{\circ} \mathbf{C}\right)$ & $\mathbf{T}_{\max }\left({ }^{\circ} \mathbf{C}\right)$ & $\mathbf{T}_{\text {end }}\left({ }^{\circ} \mathbf{C}\right)$ \\
\hline POM & 153.93 & 148.53 & 138.17 \\
POM / 0.5\%HAP & 154.17 & 149.7 & 139.23 \\
POM / 1.0\%HAP & 154.17 & 148.56 & 139.03 \\
POM / 2.5\%HAP & 153.86 & 151.02 & 138.04 \\
POM / 5.0\%HAP & 154.99 & 153.35 & 147.32 \\
\hline
\end{tabular}

Table 3.11: Effect of polytetrafluorethylene (PTFE) on Avrami coefficients for nonisothermal crystallization [49].

\begin{tabular}{c|ccc|ccc}
\hline & \multicolumn{3}{|c|}{ POM } & \multicolumn{3}{c}{ POM + PTFE } \\
$\Phi\left({ }^{\circ} \mathbf{C} \mathbf{~ m i n}^{-1}\right)$ & $\mathbf{n}$ & $\mathbf{Z}_{\mathbf{t}}$ & $\mathbf{Z}_{\mathbf{c}}$ & $\mathbf{n}$ & $\mathbf{Z}_{\mathbf{t}}$ & $\mathbf{Z}_{\mathbf{c}}$ \\
\hline 5 & 4.89 & 0.13 & 0.67 & 3.51 & 0.12 & 0.65 \\
10 & 4.31 & 1.78 & 1.06 & 3.85 & 1.53 & 1.04 \\
20 & 3.95 & 9.57 & 1.12 & 3.3 & 5.69 & 1.09 \\
40 & 3.75 & 43.85 & 1.1 & 3.65 & 31.84 & 1.09 \\
\hline
\end{tabular}

Table 3.12: Effect of attapugite, diatomite, MultiWall Carbon NanoTubes (MWCNT) [54], Hexamethylene diamine-Formaldehyde condensate (HF) [50], attapugite and diatomite silicates [51], polyamide 12 (PA) [52] on Avrami coefficients for isothermal crystallization from molten state measured by DSC, *corrected with induction period of crystallization. 
E Richaud . Polyoxymethylene Additives. In: "Polyoxymethylene Handbook: Structure, Properties, Applications and Their Nanocomposites". Sigrid Lüftl, Visakh P.M., Sarath Chandran, editors. 2014. Chap 3, pp 53-105. DOI: 10.1002/9781118914458.ch3

\begin{tabular}{|c|c|c|c|c|}
\hline $\mathbf{T}\left({ }^{\circ} \mathrm{C}\right)$ & material & $\mathbf{n}$ & $\mathbf{k}$ & $t_{1 / 2}(\mathrm{~min})$ \\
\hline 151 & POM & 2.98 & $1.08 \mathrm{E}-04$ & 18.95 \\
\hline 151 & POM + attapugite & 3.08 & $1.52 \mathrm{E}-02$ & 3.46 \\
\hline 151 & $\mathrm{POM}+$ diatomite & 3.14 & $1.33 \mathrm{E}+00$ & 0.81 \\
\hline 152 & POM & 3.72 & $3.71 \mathrm{E}-04$ & 7.71 \\
\hline 152 & $\mathrm{POM}+0.2 \% \mathrm{PA}$ & 4.12 & 4.62E-04 & 6.35 \\
\hline 152 & $\mathrm{POM}+0.4 \% \mathrm{PA}$ & 4.17 & $3.56 \mathrm{E}-03$ & 3.62 \\
\hline 152 & $\mathrm{POM}+0.6 \% \mathrm{PA}$ & 4.48 & $1.57 \mathrm{E}-02$ & 2.39 \\
\hline 152 & POM & 3 & $7.60 \mathrm{E}-04$ & 7.9 \\
\hline 152 & $\mathrm{POM}+0.05 \% \mathrm{HF}$ & 4.1 & $5.30 \mathrm{E}-03$ & 4.5 \\
\hline 152 & $\mathrm{POM}+0.2 \% \mathrm{HF}$ & 3.3 & $1.60 \mathrm{E}-03$ & 4.9 \\
\hline 152 & $\mathrm{POM}+0.5 \% \mathrm{HF}$ & 3.2 & $1.90 \mathrm{E}-03$ & 6.20 \\
\hline 154 & POM & 2.58 & $1.50 \mathrm{E}-02$ & $8.74 *$ \\
\hline 154 & $\mathrm{POM}+0.5 \% \mathrm{MWCNT}$ & 2.33 & $1.03 \mathrm{E}+00$ & $6.24 *$ \\
\hline 154 & $\mathrm{POM}+2 \% \mathrm{MWCNT}$ & 1.71 & $1.49 \mathrm{E}+00$ & $6.18 *$ \\
\hline 154 & $\mathrm{POM}+5 \% \mathrm{MWCNT}$ & 1.5 & $1.54 \mathrm{E}+00$ & $5.70 *$ \\
\hline
\end{tabular}

Table 3.13: Effect of MultiWall Carbon NanoTubes (MWCNT), Montmorillonite, polyvinylidenefluoride (PVDF) and polyamide (PA) on morphology of crystallized POM $[54,63,65,66]$.

\begin{tabular}{|c|c|c|c|}
\hline Material & $\mathbf{T}_{\mathbf{C}}\left({ }^{\circ} \mathbf{C}\right)$ & $\mathbf{H}_{\mathbf{C}}\left(\mathbf{J ~ g ~}^{-\mathbf{1}}\right)$ & $\mathbf{x}_{\mathbf{C}} \mathbf{( \% )}$ \\
\hline POM & 142.90 & & 48.3 \\
\hline POM + 0.5\%MWCNT & 146.10 & & 49.4 \\
\hline POM + 5\%MWCNT & 147.70 & & 49.4 \\
\hline POM + 5\%MWCNT & 148.60 & & 48.6 \\
\hline POM & 142.01 & 135.2 & \\
\hline POM + Na-MMT & 143.39 & 125.2 & \\
\hline POM + organ-MMT & 143.18 & 125.7 & \\
\hline POM & 142.39 & 164.9 & \\
\hline POM + PVDF & 144.52 & 131.0 & \\
\hline POM & & & 72.8 \\
\hline POM + 0.2\% PA & & & 72.5 \\
\hline POM + 0.4\% PA & & & 81.2 \\
\hline POM + 0.6\% PA & & & 85.3 \\
\hline
\end{tabular}

These tables call for the following comments:

- As expected considering the crystallization rate of pure polymer, the effect on $T_{C}$ is generally relatively low compared for example with PP.

- Nucleating agents effect on Avrami's exponent is generally lower than on crystallization kinetic constant, consistently with the fact that they accelerate nucleation. 
E Richaud . Polyoxymethylene Additives. In: "Polyoxymethylene Handbook: Structure, Properties, Applications and Their Nanocomposites”. Sigrid Lüftl, Visakh P.M., Sarath Chandran, editors. 2014. Chap 3, pp 53-105. DOI: 10.1002/9781118914458.ch3

- Under the same cooling rate, $Z_{C}$ is found higher for POM than for POM/PVDF blend. It is indicated that the PVDF hinders the growth of POM crystallite under non-isothermal condition whereas it increases the peak temperatures and decreases crystallization. In other words, PVDF accelerate the nucleation but not the growth of crystalline zone.

- The effect of MWCNT is noticeably different from the other nucleating compounds because they seem to have a significant nucleating effect. Let us mention however that graphitized CNT are on the contrary reported to have no influence on crystallization [53]. The effect of Single wall CNT was shown to be improved in presence of supercritical $\mathrm{CO}_{2}$ [54].

- Polyamide are both efficient nucleating agents [55] and thermal stabilizers.

- Last, in the case of PUR reinforced POM, those effect are less marked [56].

\subsection{Pigments and dyes}

The natural POM exhibits a translucent white color. It is colored using granular masterbatch, liquid concentrates and color compounds. Colorants are divided into two categories:

- Dyes, which are soluble.

- Organic and mineral pigments, which are insoluble.

Pigments and dyes are characterized by transparency, heat stability, light fastness, weather fastness, migration (Fig. 3.4) [57]:

Heat resistance

Lightfastness

Weather fastness

Migration

Transparency
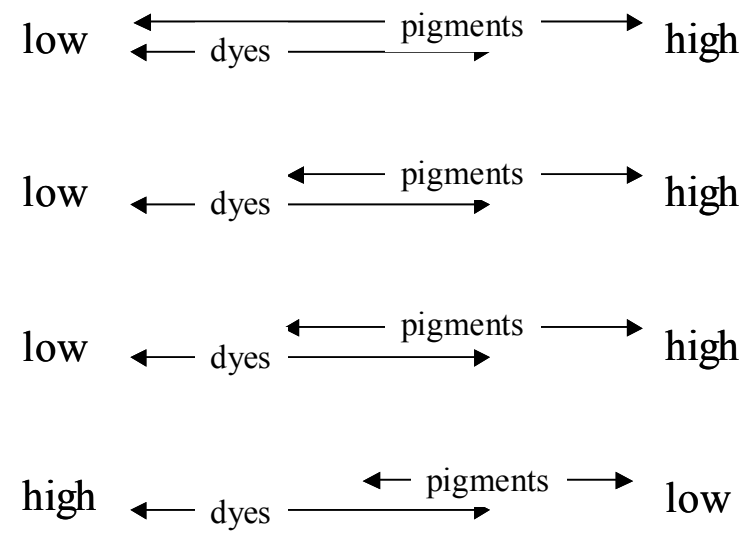

Figure 3.4: A comparison of properties of pigments and dyes. 
E Richaud . Polyoxymethylene Additives. In: "Polyoxymethylene Handbook: Structure, Properties, Applications and Their Nanocomposites". Sigrid Lüftl, Visakh P.M., Sarath Chandran, editors. 2014. Chap 3, pp 53-105. DOI: 10.1002/9781118914458.ch3

They are added to polymers by several ways:

- Powder pigments, produced by chemical industry.

- Pigments granulates, compacted form of pigments.

- Masterbatches being carrier resin of similar chemical structure to the polymer to be colored.

- Liquid or solid concentrates, based on resins of broader compatibility and thus suitable for formulating concentrates for a wide variety of polymers.

In POM color compounds are generally produced by single pigments or broad compatibility monopigments concentrates, although custom color masterbatches are also available.

\subsubsection{Mineral pigments}

Common mineral pigments are $\mathrm{TiO}_{2}$ anatase, rutile or brookite (white), FeOOH (yellow), $\mathrm{Fe}_{2} \mathrm{O}_{3}$ (red), $\mathrm{Cr}_{2} \mathrm{O}_{3}$ (green) $\mathrm{CoO}, \mathrm{Al}_{2} \mathrm{O}_{3}$ (blue) and carbon black. Generally, pigments improve the light and thermal stability of unstabilized polymer [58]. However, their role may be much more complex as illustrated in the two following cases:

(1) $\mathrm{TiO}_{2}$ may favor the oxidation of polymer by the so-called photocatalytic effect, of which mechanism is recalled in $[59,60]$. At $\mathrm{TiO}_{2}$ surface, in presence of moisture, $\mathrm{Ti}^{4+} \mathrm{HO}^{-}$is formed. At the lowest vacant conduction band:

$$
\mathrm{Ti}^{4+}+\mathrm{HO}^{-}+\mathrm{h} v \rightarrow\left(\mathrm{e}^{-}\right)^{*}+\mathrm{p}^{+}
$$

$(\mathrm{e}-)^{*}$ moves in the lowest vacancy band. The excitron $\left(\mathrm{e}^{-}\right)^{*}$ and the electronic hole $\mathrm{p}^{+}$will react with the $\mathrm{HO}^{-}+\mathrm{H}^{+}$coming from water acidobasic equilibrium.

$(\mathrm{LV}) \mathrm{Ti}^{4+}+\mathrm{e}^{-} \rightarrow \mathrm{Ti}^{3+}$

$(\mathrm{LV}) \mathrm{O}_{2}+\mathrm{Ti}^{3+} \rightarrow \mathrm{Ti}^{4+}+\mathrm{O}_{2}^{\mathrm{o}^{-}}$

$(\mathrm{LV}) \mathrm{O}_{2}^{\circ-}+\mathrm{H}^{+} \rightarrow \mathrm{HOO}^{\circ}$

$(\mathrm{HO}) \mathrm{p}^{+}+\mathrm{HO}^{-} \rightarrow \mathrm{HO}^{\circ}$

$\mathrm{Ti}^{4+} \mathrm{HO}^{-}$is regenerated after having catalyzed the reaction: $\mathrm{H}_{2} \mathrm{O}+\mathrm{O}_{2} \rightarrow \mathrm{HOO}^{\circ}+\mathrm{HO}^{\circ}$, both radicals being highly reactive and able to initiate oxidation in polymer. The surface chemistry 
E Richaud . Polyoxymethylene Additives. In: "Polyoxymethylene Handbook: Structure, Properties, Applications and Their Nanocomposites”. Sigrid Lüftl, Visakh P.M., Sarath Chandran, editors. 2014. Chap 3, pp 53-105. DOI: 10.1002/9781118914458.ch3 of $\mathrm{TiO}_{2}$ influences this phenomenon: it is in particular well known $[58,61]$ that this effect becomes negligible when $\mathrm{TiO}_{2}$ is coated with $\mathrm{Al}_{2} \mathrm{O}_{3}$.

(2) Carbon black, that is a hyperconjugated structure of graphene groups with a surface chemistry depending on its elaboration process with the coexistence of hydroxyl and carbonyl groups. Carbon black may contribute to stabilization by two different ways [62]:

- The reaction between aromatic conjugated aromatic nuclei and radicals [63,64]:

$\mathrm{P}^{\circ}+\mathrm{CB} \rightarrow$ inactive product

$\mathrm{POO}^{\circ}+\mathrm{CB}-\mathrm{OH} \rightarrow$ inactive product

- Hydroxyl and carbonyl groups present at the carbon black surface may adsorb stabilizers molecules [65], thus inhibiting their migration to the polymer superficial layers and subsequent reactions with their 'targets' $\left(\mathrm{POO}^{\circ}, \mathrm{POOH}\right.$, etc. $)$.

\subsubsection{Organic pigments and dyes}

Organic pigments display bright colors, lower heat stability. Their resistance to migration must be evaluated also. Some anthaquinone dies are reported to favor photo-oxidation in the case of polyolefins because of the following photochemically induced process:

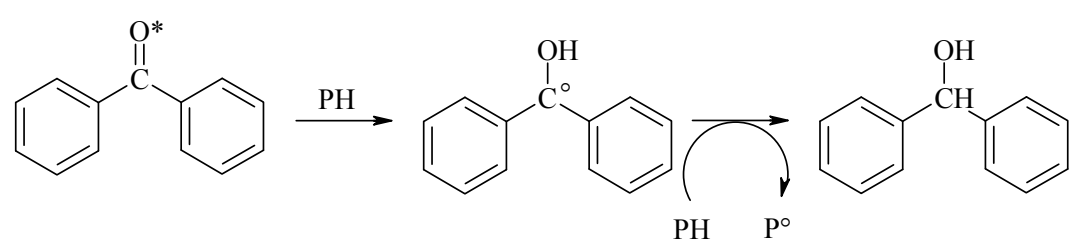

The choice of pigments involves a reverse engineering approach for the choice of UV stabilizers, which is the reason why UV absorbers or HALS stabilizers can be added to the masterbatch.

Several organic pigments can become partially soluble in very low concentrations leading to unstable shades. Soluble dyes are not recommended for coloring POM due to their potential to bloom from the polymer matrix. Care must be taken when selecting colorants for POM. When 
E Richaud . Polyoxymethylene Additives. In: "Polyoxymethylene Handbook: Structure, Properties, Applications and Their Nanocomposites”. Sigrid Lüftl, Visakh P.M., Sarath Chandran, editors. 2014. Chap 3, pp 53-105. DOI: 10.1002/9781118914458.ch3

browsing pigments datasheets, one sees that pigments thermally and chemically stable in POM are suitable for example in polyolefins but the reverse is not necessarily true.

\subsubsection{Conclusion}

Despite the relative chemical instability of POM, a substantial number of suitable organic pigments is available and are generally preferred to soluble dyes and inorganic pigments.

For unstabilized polymers, pigments play a stabilizing role in photo-oxidation by increasing the opacity of polymer and also increase the thermal stability. Pigment-polymer-stabilizer interaction is much more complex (stabilizer must protect matrix and pigment without being adsorbed at pigment surface, which depends on pigment crystalline form and flocculating properties [29]) and much comprehensive works remain to be done to understand it better.

Residence time, shear, process temperatures and nozzles and screw parameters (speed, pressure) must also be chosen according to pigment heat stability, and possible color variations due to process induced granulometry changes for pigments.

Last, pigments must play the role of nucleating agents and their influence on shrinkage and dimensional stability must be evaluated for injection molding processed materials.

\subsection{Flame retardants}

\subsubsection{Principles of combustion}

The mechanism of combustion can be summarized by figure 3.5 . 
E Richaud . Polyoxymethylene Additives. In: "Polyoxymethylene Handbook: Structure, Properties, Applications and Their Nanocomposites”. Sigrid Lüftl, Visakh P.M., Sarath Chandran, editors. 2014. Chap 3, pp 53-105. DOI: 10.1002/9781118914458.ch3

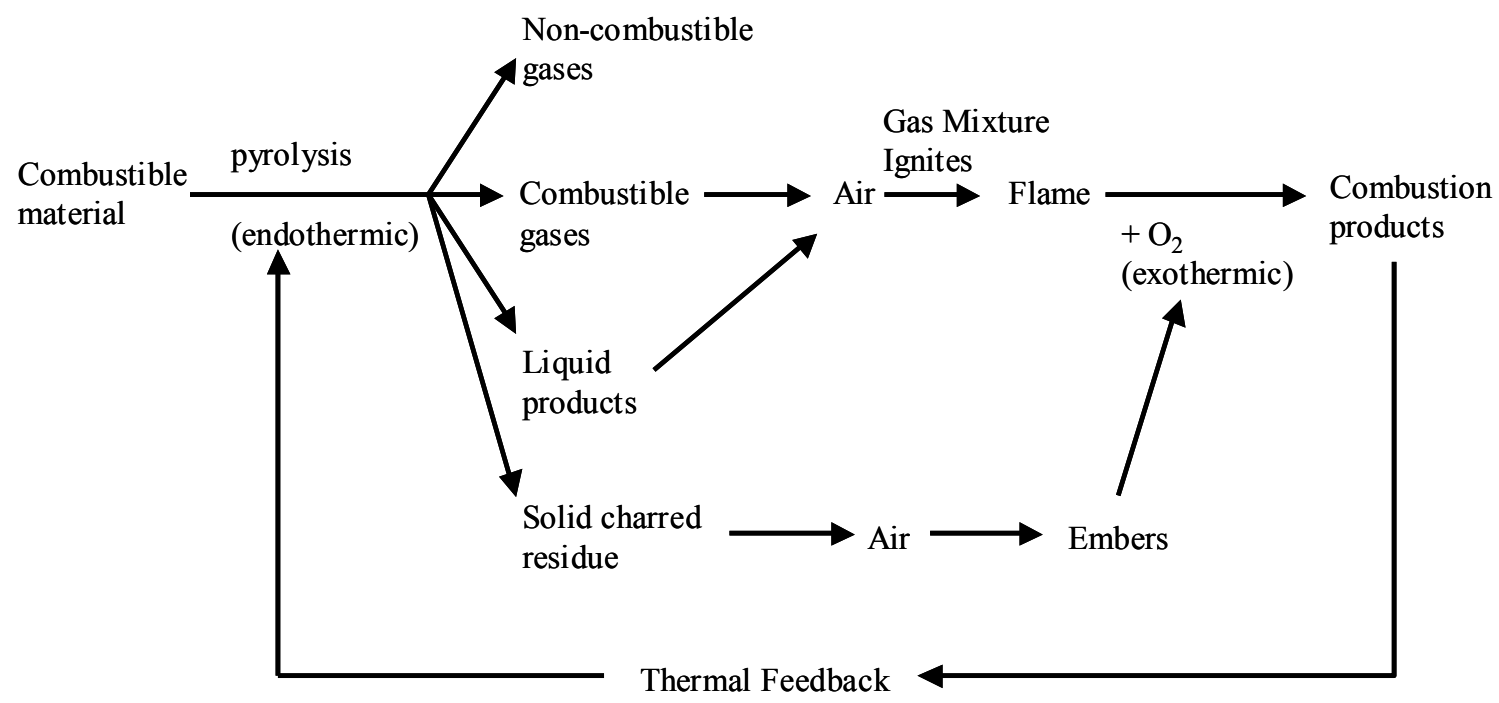

Figure 3.5: The four steps of the combustion process [66].

External heat generates volatile materials. Their combustion in gaseous phase releases heat that is transferred back to the polymer so that combustion goes on. The fire resistance of material is characterized by three sorts of data:

(1) The limiting oxygen index (LOI) which is the minimal oxygen fraction in $\mathrm{N}_{2} / \mathrm{O}_{2}$ mixtures for permitting combustion. POM has one of the lowest LOI (ca 15\%) among common polymers (table 3.14), and is hence one of the most difficult to be flame retarded.

Table 3.14: Oxygen Index of several polymers [67,68,69,70].

\begin{tabular}{cccccccc}
\hline POM & PP & PS & PET & PA66 & PVC & PVDC & PTFE \\
\hline 15.0 & 17.5 & 17.8 & 20.0 & 24.9 & 40.3 & 60.0 & 95.0 \\
\hline
\end{tabular}

(2) The UL-94: a sample of specified dimensions is suspended over a surgical cotton. The sample is heated with a Bunsen burner for 10 seconds followed by 10 second after the first test sample flames extinguishes. Five specimens are evaluated. Samples are classified V-0, V1 or V-2 based on the following criteria (table 3.15):

Table 3.15: Material ranking for UL-94 test.

\begin{tabular}{|c|c|c|c|}
\hline & V0 & V1 & V2 \\
\hline afterflame time & $<10 \mathrm{~s}$ & $<30 \mathrm{~s}$ & $<30 \mathrm{~s}$ \\
\hline um of afterflame times (for 10 application & $<50 \mathrm{~s}$ & $<250 \mathrm{~s}$ & $<250 \mathrm{~s}$ \\
\hline ignition of coton by buming drips & no & no & yes \\
\hline persitence fo flame after 2d ignition & $<30 \mathrm{~s}$ & $<60 \mathrm{~s}$ & $<60 \mathrm{~s}$ \\
\hline
\end{tabular}


E Richaud . Polyoxymethylene Additives. In: "Polyoxymethylene Handbook: Structure, Properties, Applications and Their Nanocomposites”. Sigrid Lüftl, Visakh P.M., Sarath Chandran, editors. 2014. Chap 3, pp 53-105. DOI: 10.1002/9781118914458.ch3

POM is generally not ranked which means that it behaves worse than V2 materials.

(3) The results of a cone calorimetry measurement used to evaluate the flammability of samples under an external heat flux of $35 \mathrm{~kW} \cdot \mathrm{m}^{-2}$, with specimen dimension of $100 \mathrm{~mm} \times 100 \mathrm{~mm} \times 3 \mathrm{~mm}$ according to ISO $5660-1$ standard. A typical curve is shown in Fig. 3.6.

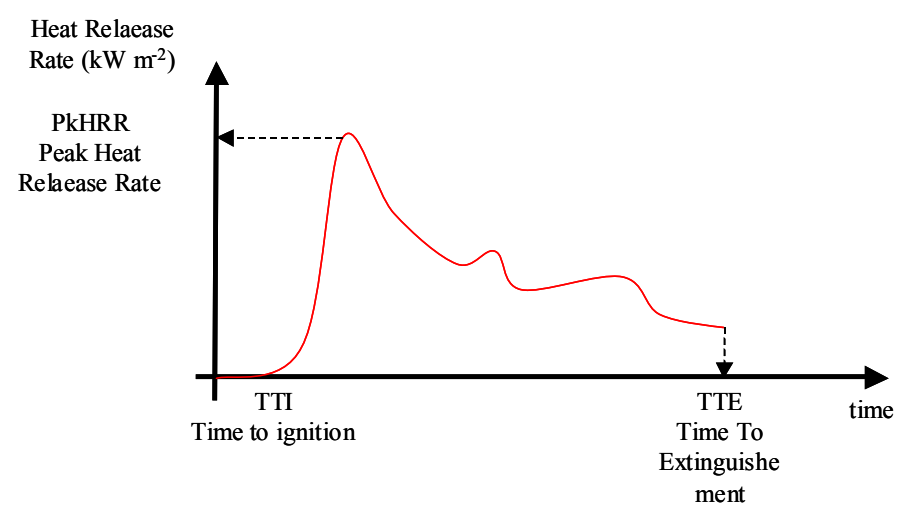

Figure 3.6: Heat release rate versus time for material combustion during cone calorimetry test.

The measured parameters of combustion performance include:

- time to ignition (TTI),

- time to extinguishment (TTE),

- peak heat release rate $(\mathrm{PkHRR})$,

- average heat release rate (AvHRR),

- fire hazard risk index (the ratio of PkHRR to TTI, PkHRR/TTI),

- peak mass loss rate (PkMLR),

- total heat release (THR).

\subsubsection{Strategies for improving flame resistance}

Improving fire resistance of polymers can be achieved by:

(1) Decreasing temperature in the polymer using mineral fillers such as $\mathrm{Al}(\mathrm{OH})_{3}$. Its decomposition: $2 \mathrm{Al}(\mathrm{OH})_{3} \rightarrow \mathrm{Al}_{2} \mathrm{O}_{3}+3 \mathrm{H}_{2} \mathrm{O}$ is endothermic and contributes to decrease the temperature in the burning zone [71]. 
E Richaud . Polyoxymethylene Additives. In: "Polyoxymethylene Handbook: Structure, Properties, Applications and Their Nanocomposites". Sigrid Lüftl, Visakh P.M., Sarath Chandran, editors. 2014. Chap 3, pp 53-105. DOI: 10.1002/9781118914458.ch3

(2) Production of inert diluent gases: for example by the release of water (for example from $\left.\mathrm{Al}(\mathrm{OH})_{3}\right)$ or carbon dioxide, flame extinction will occur [71].

(3) Creating a layer blocking the volatile transfer from polymer to the gaseous phase and acting as a barrier: intumescence additives or MMT nanocomposites [72].

(4) Trapping radicals by halogen atoms using decabromodiphenylether or antimony trioxide $\left(\mathrm{Sb}_{2} \mathrm{O}_{3}\right)$. Halogen flame-retardants are widely used for various polymers, but generally accelerate the decomposition of POM due to the catalytic action of the halide groups [73].

\subsubsection{Examples of flame-retardants in POM}

The effect of several combinations of flame-retardants on LOI, cone calorimeter tests and UL94 one are illustrated by tables 3.16, 3.17 and 3.18.

Table 3.16: Effect of aluminum trihydrate (ATH), Melamine (ME), Novolac, red phosphorus (Red $\mathrm{Ph}$ ), ammonium polyphosphate (APP), melamine cyanurate (MC) and dipentaerythritol on LOI of POM based materials (*: [74], **: [75], ***: [76]).

\begin{tabular}{|c|c|c|c|c|c|c|c|c|c|}
\hline POM & ATH & ME & Novolac & Red Ph & APP & MC & dipentaerythritol & LOI (\%) & ref \\
\hline 100 & 0 & 0 & 0 & & & & & $<16$ & $*, * *, * * *$ \\
\hline 90 & & & & 10 & & & & 15.1 & $* * *$ \\
\hline 95 & & 5 & & & & & & 15.4 & $* * *$ \\
\hline 90 & & & 10 & & & & & 15.6 & $* * *$ \\
\hline 85 & & 5 & 10 & & & & & 17.6 & $* * *$ \\
\hline 80 & & & 10 & 10 & & & & 22.7 & $* * *$ \\
\hline 85 & & & 5 & 10 & & & & 27.8 & $* * *$ \\
\hline 68 & & & & & 24 & 8 & & 28.6 & $* *$ \\
\hline 45 & 55 & 0 & 0 & & & & & 31 & $*$ \\
\hline 45 & 40 & 0 & 15 & & & & & 34 & $*$ \\
\hline 80 & & 5 & 10 & 5 & & & & 34.2 & $* * *$ \\
\hline 56 & & & & & 33 & 11 & & 34.7 & $* *$ \\
\hline 56 & & & 4 & & 24 & 12 & 4 & 37.1 & $* *$ \\
\hline 45 & 45 & 0 & 10 & & & & & 37.5 & $*$ \\
\hline 75 & & 5 & 10 & 10 & & & & 37.5 & $* * *$ \\
\hline 56 & & & 8 & & 27 & 9 & & 40.5 & $* *$ \\
\hline 45 & 40 & 7.5 & 7.5 & & & & & 43 & $*$ \\
\hline 45 & 40 & 15 & 0 & & & & & 44 & $*$ \\
\hline 45 & 45 & 10 & 0 & & & & & 44.5 & $*$ \\
\hline 45 & 50 & 5 & 0 & & & & & 45.5 & $*$ \\
\hline 45 & 50 & 0 & 5 & & & & & 46 & $*$ \\
\hline 56 & & & 4 & & 27 & 9 & 4 & 52.8 & $* *$ \\
\hline
\end{tabular}

Table 3.17: Effect of ATH, Melamine, APP and Novolac on flame resistance measured by cone calorimetry $(*:[74], * *:[77])$. 
E Richaud . Polyoxymethylene Additives. In: "Polyoxymethylene Handbook: Structure, Properties, Applications and Their Nanocomposites". Sigrid Lüftl, Visakh P.M., Sarath Chandran, editors. 2014. Chap 3, pp 53-105. DOI: 10.1002/9781118914458.ch3

\begin{tabular}{|c|c|c|c|c|c|c|c|c|c|c|c|}
\hline POM & ATH & APP & ME & Novolac & TTI (s) & TTE (s) & THR (MJ m $\left.{ }^{-3}\right)$ & PHRR $\left(k^{\prime} ~ m^{-2}\right)$ & $t_{\mathrm{HRR}}(\mathrm{s})$ & Average HRR $\left(\mathrm{kW} \mathrm{m}^{-2}\right)$ & ref \\
\hline 100 & & & & & 66 & 298 & 63.2 & 268.8 & 230 & 175.3 & * \\
\hline 45 & 40 & & 7.5 & 7.5 & 74 & & 35.6 & 133 & 95 & 61.9 & $*$ \\
\hline 60 & & 25 & 7 & 8 & 40 & 443 & & 153.7 & & 56.9 & $* *$ \\
\hline
\end{tabular}

Table 3.18: UL Vertical Burning results of the flame retardant POM based materials (*: [91], $* *:[71], * * *:[74])$.

\begin{tabular}{ccccccccc}
\hline POM & $\mathbf{M g}(\mathbf{O H})_{2}$ & $\mathbf{A l}(\mathbf{O H})_{3}$ & APP & ME & Novolac & TPP & UL94 level (3.2 mm) & ref \\
\hline 100 & & & & & & & non rated & $*$ \\
45 & 37 & & 15 & & 3 & V2 & $* *$ \\
45 & & 45 & & 5 & 5 & & V1 & $* * *$ \\
45 & & 40 & & 5 & 10 & & V1 & $* * *$ \\
45 & & 40 & & 7.5 & 7.5 & & V1 & $* * *$ \\
45 & & 40 & & 10 & 5 & & V1 & $* *$ \\
60 & 40 & 25 & 7 & 8 & & V0 & $* *$ \\
12 & 47 & & & & 5 & 3 & V0 & $* *$ \\
45 & 35 & & & 15 & 5 & & V0 & $* *$ \\
45 & 33 & & & 15 & 5 & 2 & V0 & $*$ \\
\hline
\end{tabular}

Despite its intrinsic instability, POM can reach a satisfying level of flame resistance.

The role of $\mathrm{Al}(\mathrm{OH})_{3}$ and $\mathrm{Mg}(\mathrm{OH})_{2}$ was described in the '3.8.2. Strategies for improving flame resistance'. Novolac resin and ME could be explained by:

- The carbonized products of novolac resin could conglutinate the $\mathrm{Al}_{2} \mathrm{O}_{3}$ particles to form more continuous and consolidated char layers.

- Endothermic sublimation and decomposition of ME could further decrease the temperature of the burning zone.

- The produced gases from ME could effectively dilute oxygen and fuel gases.

Apart the case of red phosphorus, significant improve in flame resistance is obtained with a high amount of additive $\left(50 \% \mathrm{~m} / \mathrm{m} \mathrm{Al}(\mathrm{OH})_{3}\right.$ or $\left.\mathrm{Mg}(\mathrm{OH})_{2}\right)$. It can provoke severe loss of mechanical properties: for example the notched Charpy impact of POM drops from $6.9 \mathrm{~kJ} . \mathrm{m}^{-2}$ to $2.2 \mathrm{~kJ} . \mathrm{m}^{-2}$ in the case of $45 \% \mathrm{POM}+40 \% \mathrm{ATH}+10 \% \mathrm{ME}+5 \%$ Novolac. Last, some of these additives may induce a decrease in thermal stability [75].

\subsection{Antistatic agents}

Plastics combine high electrical resistivity and low dielectric constant. They readily undergo charge build-up (static electricity) causing dust pick-up, handling problems, and/or electrical discharges giving electrical shocks. These problems can be solved using [78]: 
E Richaud . Polyoxymethylene Additives. In: "Polyoxymethylene Handbook: Structure, Properties, Applications and Their Nanocomposites". Sigrid Lüftl, Visakh P.M., Sarath Chandran, editors. 2014. Chap 3, pp 53-105. DOI: 10.1002/9781118914458.ch3

(1) External antistatic additives, coating polymer by spraying or immersion.

(2) Internal antistatic additives, incorporated into the polymer matrix and working as lubricants (see section '3.10. Lubricating agents') reducing the friction induced static charge generation and migrating to the polymer surface with the generation of a thin water layer at the surface of polymer forming thus a conductive path. Some examples of internal antistatic agents are given below:

- Copolymers of ethylene oxide having certainly a structure close to ethoxylated alcohols:<smiles>CCCCCCCCCCCCCCCOCCOCCOCCOCCOCCO</smiles>

- Sodium sec-alkane sulfonate:

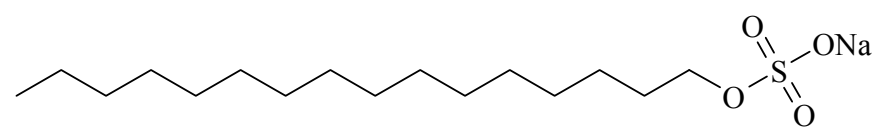

- Molecular distilled high-mono carboxylate glyceride:

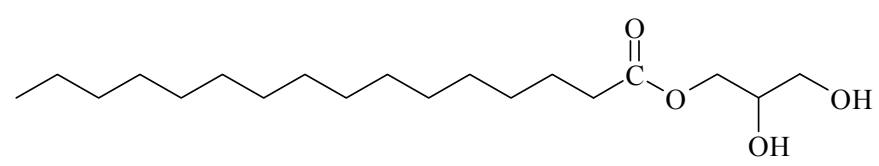

(3) Conductive fillers such as carbon black, carbon fiber, carbon nanotubes or stainless steel fiber masterbatch.

Antistatic additives are generally added to polymer matrix using a concentrated masterbatch permitting to attain a final mass fraction ca. $0.1 \%$ to $1 \%$.

\subsection{Lubricating agents}

Lubricants are used for decreasing viscosity at molten state and making processing easier at lower temperature. Two sorts of molecules with lubricating properties exist, depending on their compatibility (solubility) with polymer [79]: 
E Richaud . Polyoxymethylene Additives. In: "Polyoxymethylene Handbook: Structure, Properties, Applications and Their Nanocomposites”. Sigrid Lüftl, Visakh P.M., Sarath Chandran, editors. 2014. Chap 3, pp 53-105. DOI: 10.1002/9781118914458.ch3

(1) Internal lubricants are soluble with the polymer melt and act as sort of plasticizers. The difference between plasticizers, and lubricants is illustrated in the case of phthalates in polyvinylchloride (PVC):<smiles>[R]OC(=O)c1ccccc1C(=O)O</smiles>

solvent if $\mathrm{R}=\mathrm{CH}_{3}$ plasticizer if $\mathrm{R}=\mathrm{C}_{8} \mathrm{H}_{17}$ lubricant if $\mathrm{R}=\mathrm{C}_{18} \mathrm{H}_{37}$

(2) External lubricants are on the contrary not compatible with molten polymer and form a film at the metallic surface of process tool-polymer interface.

For example, paraffin waxes are external lubricants for PVC and internal one for polyethylene (PE). A difference in the viscosity profile between internal and external lubricants is illustrated figure 3.7 .

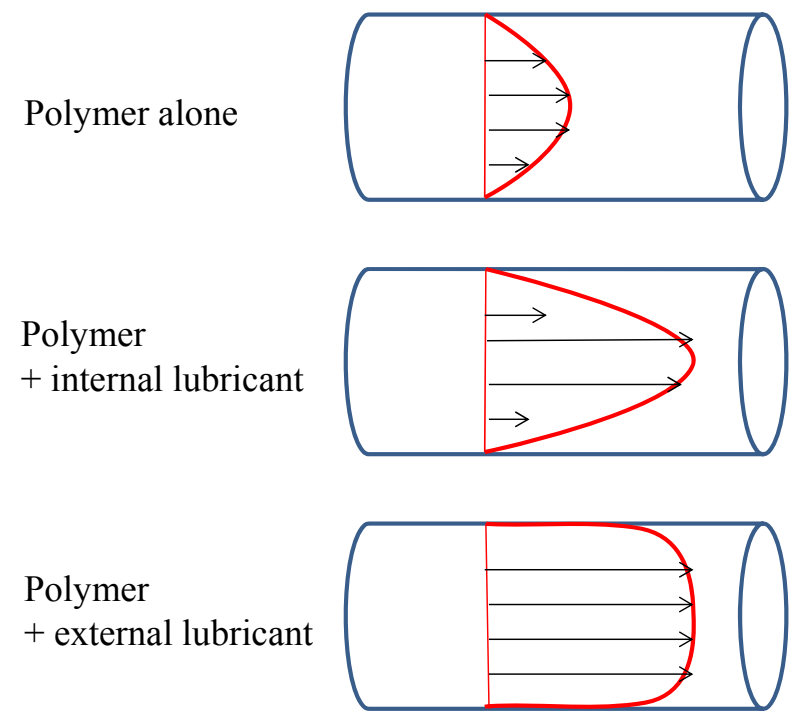

Figure 3.7: Difference in viscosity profile during processing for polymer, polymer with internal or external lubricant.

POM is processed mainly by injection molding. Its chemical reactivity makes it sensitive to acidic formulation constituent which restricts the use of carboxylic acids. Because of the high processing and service temperatures involved, suitable additives have to display good thermal stability and low volatility.

Montan waxes provide good release and flow properties, adequate compatibility, high thermal stability and good migration resistance. However, their use is limited by excessive loud cloud 
E Richaud . Polyoxymethylene Additives. In: "Polyoxymethylene Handbook: Structure, Properties, Applications and Their Nanocomposites". Sigrid Lüftl, Visakh P.M., Sarath Chandran, editors. 2014. Chap 3, pp 53-105. DOI: 10.1002/9781118914458.ch3

points or by intrinsic color which is not pure white. Micronized waxes [80], and synergistic blends of organic fatty amides, esters and glycerides [81] are met in technical literature.

The use of filler induces also a significant increase in viscosity in the molten state. The ratio of the viscosity of a suspension of spherical particles $(\eta)$ to the viscosity of the pure liquid medium $\left(\eta_{0}\right)$ is expressed using Einstein's equation [82]:

$\eta=\eta_{0} \cdot(1+\mathrm{k} . \Phi)$

$\Phi$ being the volume fraction of suspended particles. $\mathrm{k}$ is equal to 2.5 for uncompressible spherical particles. Other models are reviewed by Hanemann and co-workers [83]. A term relative to filler-filler interaction is generally added, for example in Thomas model:

$\eta=\eta_{0} \cdot\left(1+2.5 . \Phi+10.05 \cdot \Phi^{2}+\mathrm{P}_{1} \cdot \exp \left(\mathrm{P}_{2} . \Phi\right)\right)$

The use of dispersants permits to decrease the filler-filler interaction and thus to reduce significantly the viscosity of the filled polymer melt and to ease the processing [84].

\subsection{Fillers}

Some general properties of common fillers are recalled in Appendix 2. Their effect on some engineering properties will be illustrated below.

\subsubsection{Effect of fillers on thermal properties}

3.11.1.1. Durability of materials submitted to thermal cycling

One of the key issues is the fiber-matrix decohesion for a material submitted to thermal cycling. A reasoning was proposed by Hancox [85]:

$$
\sigma_{L}=-\frac{\left(\alpha_{H}-\alpha_{L}\right) \cdot \Delta T \cdot E_{L} \cdot V_{H}}{V_{L} \cdot\left[\frac{E_{L}}{E_{H}}-1\right]+1}
$$


E Richaud . Polyoxymethylene Additives. In: "Polyoxymethylene Handbook: Structure, Properties, Applications and Their Nanocomposites". Sigrid Lüftl, Visakh P.M., Sarath Chandran, editors. 2014. Chap 3, pp 53-105. DOI: 10.1002/9781118914458.ch3

$\mathrm{L}$ subscript corresponds to filler and $\mathrm{H}$ to matrix. If $\mathrm{E}_{\mathrm{L}}>\mathrm{E}_{\mathrm{H}}$, and typically, $\mathrm{V}_{\mathrm{L}}=1-\mathrm{V}_{\mathrm{H}} \sim$ 0.5 :

$\sigma_{\mathrm{L}}=-\left(\alpha_{\mathrm{H}}-\alpha_{\mathrm{L}}\right) \cdot \Delta \mathrm{T} \cdot \mathrm{E}_{\mathrm{H}}=-\sigma_{\mathrm{H}}$

In other words, fillers must fulfil the condition: $\sigma_{H}<\sigma_{R}, \sigma_{R}$ being the POM stress at break.

\subsubsection{Changes in transport and storage properties}

Commonly used polymer materials are good electrical and thermal insulators. Recent applications of polymers as heat sinks in electronic packaging require new composites with relatively high thermal conductivity. Knowledge of heat transfer in polymer is also necessary for process simulation leading to improved processing equipment, materials design and reduced cycle times, elimination of hot spots causing material degradation, or excessive temperature gradients leading to internal stresses. We will here focus on two properties characterizing the thermal behavior of polymer:

- the specific heat capacity: $\quad \mathrm{c}_{\mathrm{P}}=\frac{\partial}{\partial \mathrm{m}}\left[\frac{\partial \mathrm{H}}{\partial \mathrm{T}}\right]_{\mathrm{P}} \sim 1375 \mathrm{~J} \cdot \mathrm{kg}^{-1} \cdot \mathrm{K}^{-1}$ for POM

- the thermal conductivity: $\quad \mathrm{j}_{\mathrm{X}}=\frac{1}{\mathrm{~A}} \cdot \frac{\mathrm{dH}}{\mathrm{dt}}=-\lambda \cdot \frac{\mathrm{dT}}{\mathrm{dx}} \sim 0.35-0.39 \mathrm{~W} \cdot \mathrm{m}^{-1} \cdot \mathrm{K}^{-1}$ for POM

- from which one can calculate the thermal diffusivity:

$$
\mathrm{D}_{\text {th }}=\frac{\lambda}{\rho \cdot \mathrm{c}_{\mathrm{P}}} \sim 1.8 \times 10^{-7} \mathrm{~m}^{2} \cdot \mathrm{s}^{-1} \text { for POM }
$$

Some examples of thermal conductivity or heat capacity changes with volume fraction of fillers like copper $(\mathrm{Cu})$, cellulose fibers, graphite, carbon nanotubes (MWCNT) and polyethyleneglycol (PEG) are shown in figure 3.8. 
E Richaud . Polyoxymethylene Additives. In: "Polyoxymethylene Handbook: Structure, Properties, Applications and Their Nanocomposites". Sigrid Lüftl, Visakh P.M., Sarath Chandran, editors. 2014. Chap 3, pp 53-105. DOI: 10.1002/9781118914458.ch3
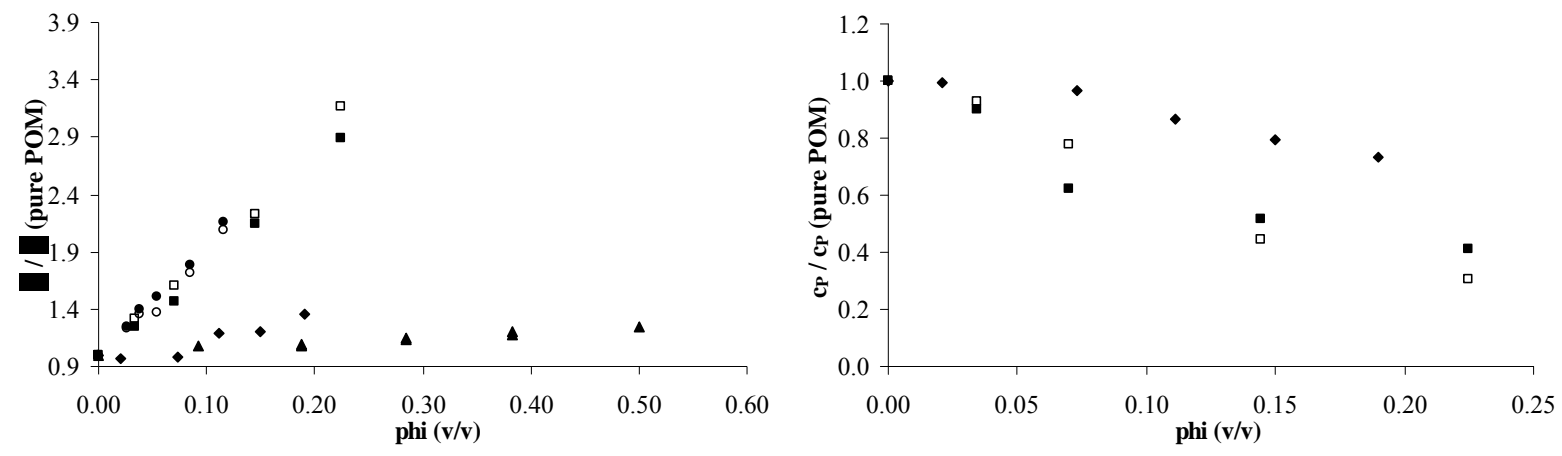

Figure 3.8: Relative changes in heat conductivity and heat capacity for $\mathrm{POM}+\mathrm{Cu}(\diamond)[86]$,

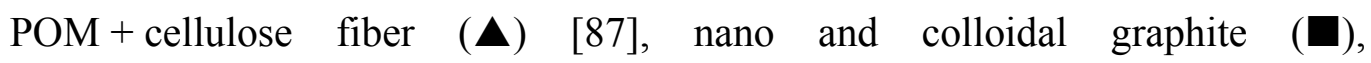
polyoxymethylene/graphite composites ( $\square$ ) [88], polyoxymethylene/carbon nanotubes compatilized with $10 \%(\bigcirc)$ and $15 \%(\bigcirc)$ PEG [89].

Graphite and MWCNT improve significantly thermal conductivity, having also the advantage of limit the mass increase compared for example to copper. All investigated additives involve a decrease in heat capacity, and in other word an increase in heat diffusion coefficient.

Several models are aimed at predicting the conductivity of a composite. Most of them were recently reviewed by [90]. One can propose models for serial or parallel elements:

$$
\begin{aligned}
& \lambda_{\mathrm{c}}=\lambda_{\mathrm{m}} \cdot\left(1-\phi_{\mathrm{f}}\right)+\lambda_{\mathrm{f}} \cdot \phi_{\mathrm{f}} \\
& \frac{1}{\lambda_{\mathrm{c}}}=\frac{\left(1-\phi_{\mathrm{f}}\right)}{\lambda_{\mathrm{m}}}+\frac{\phi_{\mathrm{f}}}{\lambda_{\mathrm{f}}}
\end{aligned}
$$

where $\lambda_{\mathrm{c}}, \lambda_{\mathrm{m}}$ and $\lambda_{\mathrm{f}}$ are respectively the thermal conductivity of composite, matrix and filler.

Other models exist $[91,92]$ but it seems that these two models fit relatively well in coarse grain studies. The most refined equations versions are aimed at describing effect of filler geometry, as for example Hatta Taya model in the case of spherical inclusions [93]:

$$
\frac{\lambda_{\mathrm{c}}}{\lambda_{\mathrm{m}}}=1+\frac{\phi_{\mathrm{f}}}{\frac{1-\phi_{\mathrm{f}}}{3}+\frac{\lambda_{\mathrm{m}}}{\lambda_{\mathrm{f}}-\lambda_{\mathrm{m}}}}
$$

Practitioners also use the Agari's model [94]: 
E Richaud . Polyoxymethylene Additives. In: "Polyoxymethylene Handbook: Structure, Properties, Applications and Their Nanocomposites". Sigrid Lüftl, Visakh P.M., Sarath Chandran, editors. 2014. Chap 3, pp 53-105. DOI: 10.1002/9781118914458.ch3

$\log \lambda_{\mathrm{c}}=\Phi_{\mathrm{f}} \cdot \mathrm{C}_{2} \cdot \log \lambda_{\mathrm{f}}+\left(1-\Phi_{\mathrm{f}}\right) \cdot \log \left(\lambda_{\mathrm{m}} \cdot \mathrm{C}_{1}\right)$

where $C_{1}$ is a factor related to the polymer microstructure and $C_{2}$ a factor related to the ease of filler percolation (table 3.19).

Table 3.19: Agari's coefficient for POM grafted with MWCNT [89] and graphite [95].

\begin{tabular}{|c|c|c|}
\hline & C1 & C2 \\
\hline POM/MWCNT-g-PEG-10 & 1.045 & 0.928 \\
\hline POM/MWCNT-g-PEG-15 & 1.028 & 0.880 \\
\hline POM/colloidal graphite & 1.120 & 0.666 \\
\hline POM/nanographite & 1.040 & 0.655 \\
\hline
\end{tabular}

The effect of drawing was in particular illustrated by Zhao et al. [88] in the case of POM/MWCNT: orientation induces a higher gain in thermal conductivity.

\subsubsection{Effect of fillers on mechanical properties}

3.11.2.1. On Young's modulus and stress at break

Let us first mention that fillers will improves mechanical strength (Young's modulus and yield stress) because of mixing laws, which will be detailed below. They may also favor the crystallization by an interfacial phenomenon was recently reviewed [96].

The elastic modulus of composite materials reinforced by discontinuous cylindrical fibers or lamellar shapes is expressed by the Halpin-Tsai equations [97]:

$$
\mathrm{E}=\mathrm{E}_{\mathrm{m}} \cdot\left[\frac{1+\xi \eta \Phi}{1-\eta \Phi}\right]
$$

where:

- $\xi$ is a measure of reinforcement geometry, which depends on loading conditions.

- And: $\eta=\frac{E_{f} / E_{m}-1}{E_{f} / E_{m}+\xi}$ 
E Richaud . Polyoxymethylene Additives. In: "Polyoxymethylene Handbook: Structure, Properties, Applications and Their Nanocomposites". Sigrid Lüftl, Visakh P.M., Sarath Chandran, editors. 2014. Chap 3, pp 53-105. DOI: 10.1002/9781118914458.ch3

Hashemi [43] used the following derived relationships in the case of tensile and flexural stress and modulus from POM filled with beads and fibers:

$\mathrm{E}_{\mathrm{POM} / \mathrm{filler}}=\mathrm{E}_{\mathrm{POM}} \cdot\left(1+\mathrm{k}_{1} \cdot \Phi_{\text {filler }}\right)$

$\sigma_{\mathrm{POM} / \text { filler }}=\sigma_{\mathrm{POM}} \cdot\left(1+\mathrm{k}_{2} \cdot \Phi_{\text {filler }}\right)$

In the following, we will consider rather mass fraction, which is an engineering measure, instead of volume fraction. An example of curves for mechanical properties changes with filler content is shown in figure 3.9.

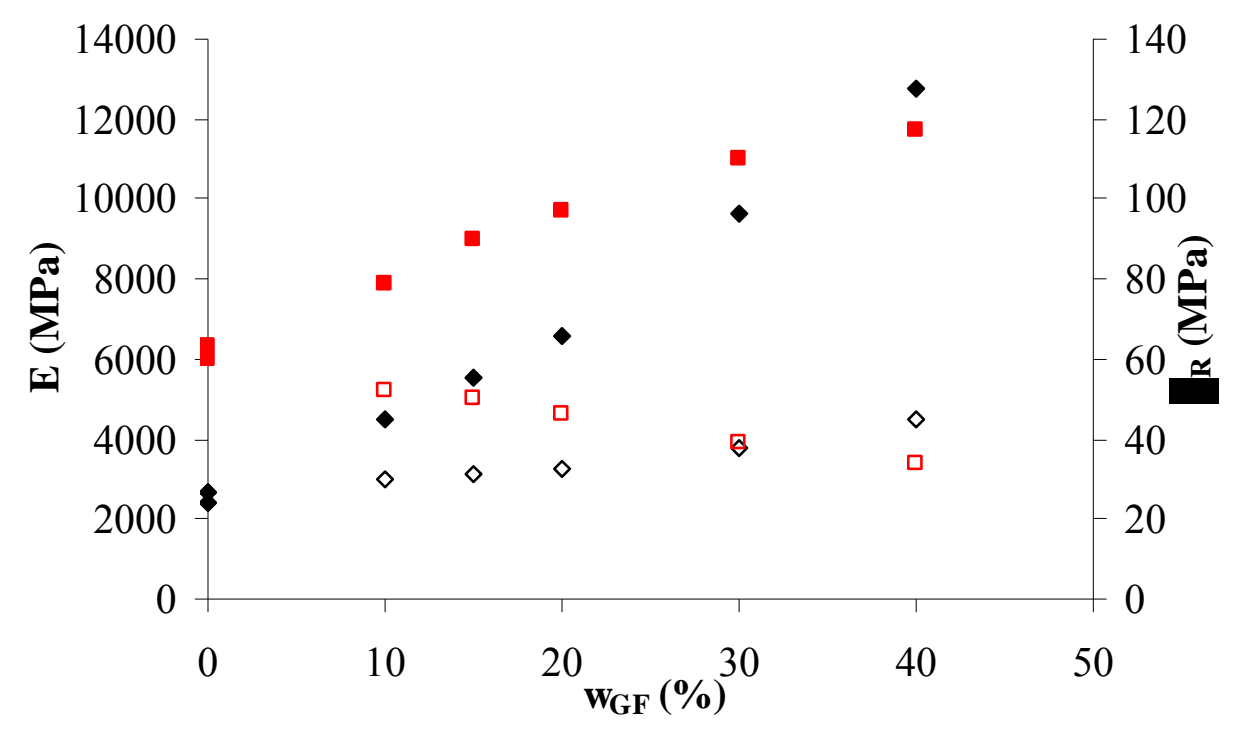

Figure 9. Young' modulus $(\diamond, \diamond)$ and stress at break $(\boldsymbol{\square}, \square)$ for POM reinforced with glass beads (open symbols) and glass fibers (closed symbols) [98].

Literature illustrates the changes of Young's modulus with MWCNT $(\mathrm{k} \sim 30)$ [40], glass fibers $(\mathrm{k} \sim 10)$, cellulose $(\mathrm{k} \sim 4)$ [99], glass beads $(\mathrm{k} \sim 2.5)$ [57], $\mathrm{ZnO}(\mathrm{k} \sim 2)$ [100], carbon fibers $(\mathrm{k} \sim 1.5)$ [101], and organoclays $(\mathrm{k} \sim 0.5)$ [102].

The compiled results call for the following comments:

- Bashtanik et al [103] illustrated the effect of organosilicon finishes on POM + cellulose fibers properties, showing an optimal mass fraction of finishes ca $1 \%$ (for a fiber mass fraction of $20 \%$ ).

- Adding low amount of $\mathrm{SiO}_{2}$ can improve the properties of POM $+20 \%$ carbon fibers, but an optimum is reached at ca $3 \%$ for impact resistance. 
E Richaud . Polyoxymethylene Additives. In: "Polyoxymethylene Handbook: Structure, Properties, Applications and Their Nanocomposites". Sigrid Lüftl, Visakh P.M., Sarath Chandran, editors. 2014. Chap 3, pp 53-105. DOI: 10.1002/9781118914458.ch3

- Certain fillers have a negative impact on tensile properties, such as $\mathrm{TiO}_{2}$ even at low mass percentage [100]. This effect seems particularly marked when decreasing particles size. Some fillers such as PUR having a positive effect on impact strength but decrease Young's modulus and creep resistance as well [104].

- Stress at break values for POM filled with micro or nano-Cu particles or $\mathrm{ZnO}$ do not fit the above proposed relationships [105]. In the case of organoclays for example, the existence of an optimal filler mass fraction preceding a decrease in stress at break is shown [102].

\subsubsection{On elongation at break}

The effect of fillers on elongation at break is relatively complex to describe: curves displaying a maximum are generally observed in the case of MWCNT [40] or organoclays [102].

\subsubsection{Effect of fillers on electrical properties}

Electrical conductivity is defined by:

$\sigma=\frac{1}{\rho}=\frac{1}{S \times R}$

In the case of samples filled with additives improving the electrical properties, conductivity changes with filler content are illustrated in figure 3.10.

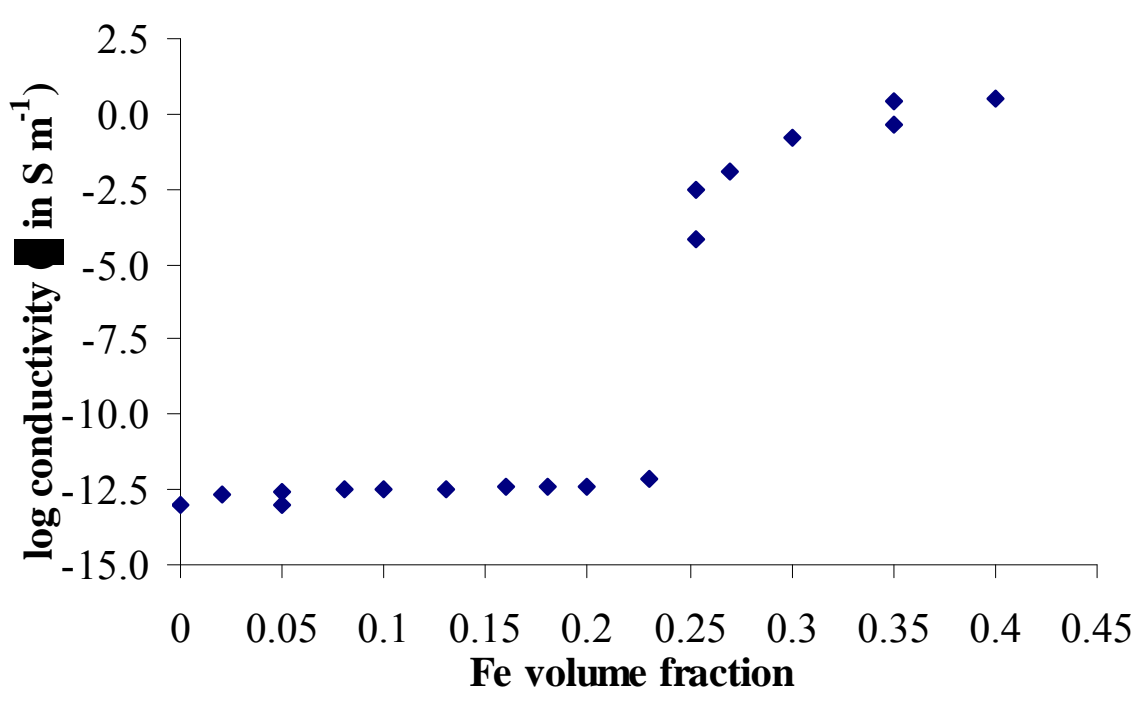

Figure 3.10: Typical conductivity changes with iron $(\mathrm{Fe})$ volume fraction. 
E Richaud . Polyoxymethylene Additives. In: "Polyoxymethylene Handbook: Structure, Properties, Applications and Their Nanocomposites”. Sigrid Lüftl, Visakh P.M., Sarath Chandran, editors. 2014. Chap 3, pp 53-105. DOI: 10.1002/9781118914458.ch3

Curves have generally the following shape:

- At relatively low filler content, the electrical properties remain almost constant and very close to the ones of pure polymer.

- A percolation threshold is expected and corresponds to a sudden increase in electrical conductivity. The jump in electrical properties would correspond to the formation of the filler network in the polymer and in other words to a jump in rheological properties as well. A short literature review indicate that $\sigma_{\mathrm{C}} \sim \mathrm{q} . \sigma_{\mathrm{P}}$, with $\sigma_{\mathrm{P}}$ being the pure polymer conductivity, $\sigma_{\mathrm{C}}$ the conductivity at the saturation threshold and $\mathrm{q} \sim 2-10$.

- Above the percolation threshold, conductivity increase with a negative curvature and plateaus at high filler content.

According to [106], the following equation can be ascribed:

$$
\sigma=\sigma_{\mathrm{C}}+\left(\sigma_{\mathrm{M}}-\sigma_{\mathrm{C}}\right) \cdot\left(\frac{\phi-\phi_{\mathrm{C}}}{\mathrm{F}-\phi_{\mathrm{C}}}\right)^{\mathrm{t}}
$$

where:

- $\phi_{\mathrm{C}}=$ percolation threshold

- $\sigma_{M}$ is the maximal conductivity

- $\sigma_{\mathrm{C}}$ is the conductivity value at the percolation threshold

- $\mathrm{F}$ is the packing factor corresponding to filler volume fraction at the beginning of the plateau.

We have thus analyzed available experimental results for determining $\phi_{C}, \sigma_{M}, \sigma_{C}$ and $F$ characterizing the filler performances in electrical properties improvement (table 3.20).

Table 3.20: Parameters of percolation law for electrical conductivity changes of POM with several additives (Fe [106], MWCNT [107,108]) $\sigma_{M}$ and $\sigma_{C}$ in S.m ${ }^{-1}, \Phi_{C}$ and $\Phi$ in volume fractions.

\begin{tabular}{|c|c|c|c|c|c|}
\hline filler & $\boldsymbol{\Phi}_{\mathbf{C}}$ & $\sigma_{\mathbf{C}}$ & $\sigma_{\mathbf{M}}$ & $\mathbf{F}$ & $\mathbf{t}$ \\
\hline CNT1 & 0,004 & $2.10^{-12}$ & 2,75 & 0,113 & 4,6 \\
\hline CNT2 & 0,004 & $2.10^{-12}$ & 2,4 & 0,05 & 3,76 \\
\hline Fe & 0,24 & $8.10^{-13}$ & 6 & 0,113 & 3 \\
\hline
\end{tabular}


E Richaud . Polyoxymethylene Additives. In: "Polyoxymethylene Handbook: Structure, Properties, Applications and Their Nanocomposites”. Sigrid Lüftl, Visakh P.M., Sarath Chandran, editors. 2014. Chap 3, pp 53-105. DOI: 10.1002/9781118914458.ch3

Fe permits the best improvement of electrical properties but with a high volume ratio (i.e. a significant increase in mass) whereas CNT significantly increase electrical properties at a low mass fraction (ca $1 \%$ ). However, they also induce a decrease in thermal stability [108].

\subsubsection{Effect of fillers on tribological properties}

Friction coefficient is the ratio of the tangential and normal force for a polymer sliding on a surface. One distinguishes:

- static friction coefficient, linked to the maximal force for permitting the motion.

- kinetic friction coefficient is linked to the average force during sliding.

The wear volume is defined as the volume of polymer which is removed when submitted to a material sliding on its surface:

$\mathrm{V}=\mathrm{k} . \mathrm{F} . \mathrm{L}$

Where:

$-\mathrm{V}$ is the wear volume.

- $\mathrm{F}$ is the normal load imposed to the sliding material

- $\mathrm{L}$ is the length of slide

Typical data are shown in table 3.21.

Table 3.21: Changes in friction and abrasion coefficient of POM with several additives graphite (C), polyethyleneoxide (PEO) $(*$ : [109], **: [110], ***: [111]). 
E Richaud . Polyoxymethylene Additives. In: "Polyoxymethylene Handbook: Structure, Properties, Applications and Their Nanocomposites". Sigrid Lüftl, Visakh P.M., Sarath Chandran, editors. 2014. Chap 3, pp 53-105. DOI: 10.1002/9781118914458.ch3

\begin{tabular}{|c|c|c|c|c|}
\hline Material & $\mu$ & $k\left(10^{-6} \mathrm{~mm}^{3} \mathrm{~N}^{-1} \mathrm{~m}^{-1}\right)$ & Conditions & ref \\
\hline POM & 0.69 & 1.3 & \multirow{4}{*}{$62.5 \mathrm{~N}-0.3 \mathrm{~m} \mathrm{~s}^{-1}$} & \multirow{4}{*}{$*$} \\
\hline $\mathrm{POM}+15 \%$ PTFE & 0.24 & 0.6 & & \\
\hline $\mathrm{POM}+15 \% \mathrm{PTFE}+20 \% \mathrm{C}$ & 0.36 & 2.3 & & \\
\hline $\mathrm{POM}+15 \%$ PTFE $+20 \%$ glass & 0.33 & 6.7 & & \\
\hline POM & 0.36 & 50 & \multirow{4}{*}{$\begin{array}{c}10 \mathrm{~N}-0.1 \mathrm{~m} \mathrm{~s}^{-1} \\
\text { AISI-52100 } \\
\text { hardened steel }\end{array}$} & \multirow{4}{*}{ ** } \\
\hline $\mathrm{POM}+20 \%$ glass fibers & 0.35 & 40 & & \\
\hline POM + 20\% PTFE fibers & 0.2 & 10 & & \\
\hline $\mathrm{POM}+20 \%$ PTFE micro powder & 0.29 & 15 & & \\
\hline POM & 0.17 & 1.8 & \multirow{7}{*}{$196 \mathrm{~N}-0.4 \mathrm{~m} \mathrm{~s}^{-1}$} & \multirow{7}{*}{$* * *$} \\
\hline $\mathrm{POM}+5 \% \mathrm{PTFE}$ & 0.165 & 1.5 & & \\
\hline $\mathrm{POM}+10 \%$ PTFE & 0.14 & 1.3 & & \\
\hline $\mathrm{POM}+15 \%$ PTFE & 0.13 & 1.25 & & \\
\hline $\mathrm{POM}+20 \%$ PTFE & 0.12 & 1.2 & & \\
\hline $\mathrm{POM}+10 \% \mathrm{PEO}$ & 0.14 & 2.1 & & \\
\hline $\mathrm{POM}+15 \% \mathrm{PEO}$ & 0.145 & 2.25 & & \\
\hline
\end{tabular}

PTFE decreases friction coefficient and abrasion constant [112,113], despite some negative effects on mechanical properties. This can be improved if sodium etched PTFE is added to the mixture POM/PTFE, because sodium etching works as a compatibilization treatment [114].

$\mathrm{Al}_{2} \mathrm{O}_{3}$ [115] increases both friction coefficient and wear volume. $\mathrm{MoS}_{2}$ was shown to be poorly effective even if a slight decrease in friction coefficient was observed when using nanoballs instead of microballs [116]. A combination of aromatic vinyl modified polyethylene and fatty acid ester can also be used for POM improving sliding performances [117]. On the contrary, cellulosic carbon fibers increase friction coefficient and wear volume [117].

\subsubsection{On gas permeability}

Fillers are expected to improve barrier properties of POM by two distinct ways:

(1) It was already shown (see '3.6. Nucleating agent') that fillers help nucleation in POM. It is well known that gas is not soluble in it. Compañ [118] reported for example that if:

- D*(T) is the diffusion coefficient in a $100 \%$ amorphous polymer,

$-\mathrm{D}\left(\mathrm{x}_{\mathrm{am}}, \mathrm{T}\right)$ is the diffusion coefficient in a semi-crystalline polymer (of crystallinity $\mathrm{x}_{\mathrm{C}}$ )

One has:

$$
\frac{\mathrm{D}^{*}(\mathrm{~T})}{\mathrm{D}\left(\mathrm{x}_{\mathrm{am}}, \mathrm{T}\right)}=\exp \left(-\frac{\Delta \mathrm{G}_{\mathrm{am}}^{++}-\Delta \mathrm{G}^{++}}{\mathrm{RT}}\right)=\exp \left(-\frac{\Delta \mathrm{G}_{\mathrm{am}}^{++}}{\mathrm{RT}} \cdot \mathrm{x}_{\mathrm{C}}\right)
$$


E Richaud . Polyoxymethylene Additives. In: "Polyoxymethylene Handbook: Structure, Properties, Applications and Their Nanocomposites". Sigrid Lüftl, Visakh P.M., Sarath Chandran, editors. 2014. Chap 3, pp 53-105. DOI: 10.1002/9781118914458.ch3

According to Compañ, this equation is consistent with Michael and Bixler [119] theory:

$$
\frac{\mathrm{D}^{*}(\mathrm{~T})}{\mathrm{D}\left(\mathrm{x}_{\mathrm{am}}, \mathrm{T}\right)}=\beta . \tau
$$

Where :

- $\beta$ is the factor expressing immobilization of amorphous phase by crystalline one

$$
\beta=\exp \left(-\frac{\Delta \mathrm{H}_{\mathrm{am}}^{++}-\Delta \mathrm{H}^{++}}{\mathrm{RT}}\right)
$$

$-\tau$ is the tortuosity linked to the presence of barriers blocking diffusion of gas molecules

$$
\tau=\exp \left(\frac{\Delta \mathrm{S}_{\mathrm{am}}^{++}-\Delta \mathrm{S}^{++}}{\mathrm{R}}\right)
$$

and $[120,121]: \quad \ln \tau=-n \cdot \ln \left(1-\mathrm{x}_{\mathrm{C}}\right)$

(2) Furthermore, clay nanoparticles induce a decrease in diffusion coefficient in amorphous phase of polymer by increasing the tortuosity i.e. working as barriers blocking the gas diffusion in amorphous phase, as observed for example by Gutierrez et al. [122] for PE.

\begin{tabular}{|c|c|c|}
\hline & \multicolumn{2}{|c|}{$\mathrm{O}_{2}$ permeability $\left(\mathrm{cm}^{3} \mathrm{~mm} \mathrm{~m}^{-2}\right.$ day $^{-1}$ bar $\left.^{-1}\right)$} \\
\hline POM & 0.65 & 0.22 \\
\hline POM + NF5 & 0.44 & 0.06 \\
\hline POM + NF9 & 0.33 & 0.05 \\
\hline POM + KT & 0.3 & 0.02 \\
\hline
\end{tabular}

The effect of some nanofillers on POM permeability to gas is illustrated in table 3.22.

Table 3.22: $\mathrm{O}_{2}$ permability in bentonite filled POM [123].

\subsection{Processing aids}

Polymer Process Aids (PPA) are specifically designed to enhance extrusion ability of plastics leading to productivity and / or quality improvement as for example:

- Reduces / eliminates melt fracture.

- Eliminate sharkskin effect. 
E Richaud . Polyoxymethylene Additives. In: "Polyoxymethylene Handbook: Structure, Properties, Applications and Their Nanocomposites". Sigrid Lüftl, Visakh P.M., Sarath Chandran, editors. 2014. Chap 3, pp 53-105. DOI: 10.1002/9781118914458.ch3

- Reduce or eliminate Gels and optical defects.

- Increase the output by up to $20 \%$.

- Reduce electricity consumption due to reduced back-pressure in the extruder.

Their role is not too far from the one of lubricants (see '3.10. Lubricants'). In fact, lubricants can be considered as processing aids, but some processing aids (for easing demoulding for example) are not lubricants. They are used as masterbatches formulated to form a microscopic dispersed phase within the polymer carrier.

Silicones and silicone oil [124,125,126], acrylate copolymer [127], fluoroelastomer (Tecnoflon ${ }^{\circledR}$ NM FKM) or fluorinated thermoplastics (PVDF such as Solef® 11010) are evoked as possible processing aids for POM. During processing, these fluoropolymers coat the walls of the extruder and die, thus reducing the extruder backpressure to decrease. 
E Richaud . Polyoxymethylene Additives. In: "Polyoxymethylene Handbook: Structure, Properties, Applications and Their Nanocomposites". Sigrid Lüftl, Visakh P.M., Sarath Chandran, editors. 2014. Chap 3, pp 53-105. DOI: 10.1002/9781118914458.ch3 APPENDIX 1: LIST OF STABILIZERS<smiles>Cc1cc(CCC(=O)OCCCCC(=O)OCCc2cc(C)c(O)c(C(C)(C)C)c2)cc(C)c1O</smiles>

AO1: triethylene glycol-bis-3-(-3-tertbutyl-4-hydroxy-5-methyl phenyl)propionate<smiles>CC(C)(C)OC(=O)CCc1cc(CCC(=O)OC(C)(C)C)c(O)c(C(C)(C)C)c1</smiles>

AO2: 1,6-hexamethylenebis-3-(3,5-ditertbutyl-4-hydroxyphenyl)-propionate<smiles>CC(C)(C)NC(=O)CCc1cc(C(C)(C)C)c(O)c(C(C)(C)C)c1</smiles>

AO3: 1,6-hexamethylenebis-3-(3,5-ditertbutyl-4-hydroxyphenyl)-propionamide<smiles>CC(C)(C)COC(=O)CCc1cc(C(C)(C)C)c(O)c(C(C)(C)C)c1</smiles>

AO4: pentaerythriltyl-tetrakis-3-(3,5-ditertbutyl-4-hydroxyphenyl)-propionate<smiles>Cc1cc(Cc2cc(C)cc(C(C)(C)C)c2O)c(O)c(C(C)(C)C)c1</smiles>

AO5. 2,2-methylene-bis-(4-methyl-6 tertbutyl phenol)<smiles>Cc1cc(CCC(=O)NCCC(C)(C)OCCC(C)(C)NC(=O)CCc2cc(C)c(O)c(C(C)(C)C)c2)cc(C)c1O</smiles>

AO6: N,N'-triethylenedioxy-bis(3-tert-butyl-4-hydroxy-5methylhydroxycinnamide) 
E Richaud . Polyoxymethylene Additives. In: "Polyoxymethylene Handbook: Structure, Properties, Applications and Their Nanocomposites". Sigrid Lüftl, Visakh P.M., Sarath Chandran, editors. 2014. Chap 3, pp 53-105. DOI: 10.1002/9781118914458.ch3<smiles>[R]CCOCCOC(=O)CCc1cc(C)c(O)c(C(C)(C)C)c1</smiles>

AO7: N,N',N'”-tris[(3-tert-butyl-4-hydroxy-5-methylphenyl)-propionate-3-oxapentyl]melamine<smiles>Cc1cc(I)cc(C(C)(C)C)c1O</smiles>

AO8. 2,4-di-tertbutyl phenol<smiles>Cc1ccc(C(C)(C)C)c(O)c1</smiles>

AO9. 6 tertbutyl-m-cresol<smiles>Cc1cc(Cc2cc(C)c(O)c(C(C)(C)C)c2)cc(C(C)(C)C)c1O</smiles>

AO10. 4,4-methylene-bis-(2,methyl-6-tert butyl-phenol)<smiles>c1ccc(Nc2ccccc2)cc1</smiles>

AO 11. diphenylamine<smiles>C[Si](C)(Oc1ccccc1)Oc1ccc(Nc2ccccc2)cc1</smiles>

AO 12. dimethyldi-(phenylaminophenoxy)silane 
E Richaud . Polyoxymethylene Additives. In: "Polyoxymethylene Handbook: Structure, Properties, Applications and Their Nanocomposites". Sigrid Lüftl, Visakh P.M., Sarath Chandran, editors. 2014. Chap 3, pp 53-105. DOI: 10.1002/9781118914458.ch3<smiles>Cc1ccc2o[nH]n3c4ccccc4[nH]n3c2c1</smiles>

UVA 1.

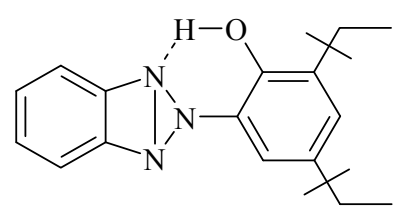

UVA 2.<smiles>CCC(C)c1cc(C(C)(C)C)cc2c1o[nH]n1c3ccccc3n21</smiles>

UVA 3.<smiles>CC(C)(c1ccccc1)c1cc(C(C)(C)c2ccccc2)c2o[nH]n3c4ccccc4n3c2c1</smiles>

UVA 4.<smiles>COC(=O)C(C)(C)C(=O)OCC(C)(C)C(=O)OCC(C)(C)N1C(C)(C)CC(OC(=O)C(C)(C)C)CC1(C)C</smiles>

HALS 1.<smiles>CN1C(C)(C)CC(OC(=O)C(C)(C)C(=O)OC2CC(C)(C)N(C)C(C)(C)C2)CC1(C)C</smiles>

HALS 2. 
E Richaud . Polyoxymethylene Additives. In: "Polyoxymethylene Handbook: Structure, Properties, Applications and Their Nanocomposites". Sigrid Lüftl, Visakh P.M., Sarath Chandran, editors. 2014. Chap 3, pp 53-105. DOI: 10.1002/9781118914458.ch3<smiles>CC1(C)CC(OC(=O)C(C)(C)C)CC(C)(C)N1</smiles>

\section{HALS 3}

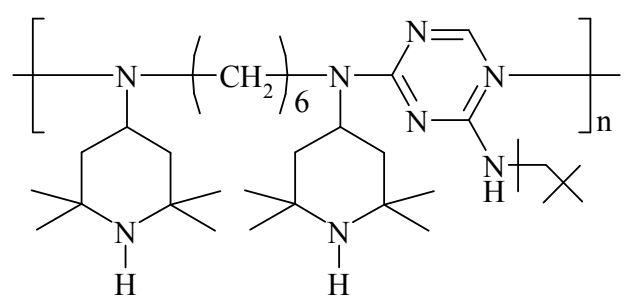

HALS 4.<smiles>[R]c1nc([R])nc(NC(C)(C)C)n1</smiles><smiles>[R]N([CH])[C@H]1C[C@H](C)C(C)(C)C(C)(C)N1C</smiles>

HALS 5.<smiles>COP(=O)([O-])OP(=O)(O[NH3+])OP(=O)(O[NH3+])OP(=O)([O-])OP(=O)([O-])OP(=O)([O-])OP(=O)([O-])O[NH3+]</smiles>

ammonium polyphosphate (APP)

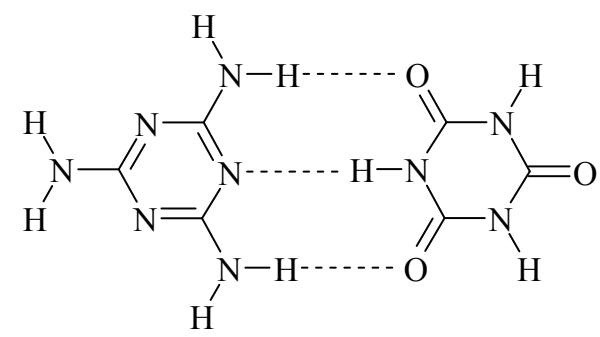

melamine cyanurate $(\mathrm{MC})$ 
E Richaud . Polyoxymethylene Additives. In: "Polyoxymethylene Handbook: Structure, Properties, Applications and Their Nanocomposites". Sigrid Lüftl, Visakh P.M., Sarath Chandran, editors. 2014. Chap 3, pp 53-105. DOI: 10.1002/9781118914458.ch3<smiles>Nc1nc(N)nc(N)n1</smiles>

Melamine<smiles>[3H][PH](=O)C1([13CH3])CC1c1ccccc1</smiles>

Triphenylphosphate<smiles>Cc1cccc(C([AlH2])c2cccc(C)c2O)c1O</smiles>

Novolac<smiles>OCC(CO)(CO)COCC(CO)(CO)CO</smiles>

Pentaerythritol 
E Richaud . Polyoxymethylene Additives. In: "Polyoxymethylene Handbook: Structure, Properties, Applications and Their Nanocomposites". Sigrid Lüftl, Visakh P.M., Sarath Chandran, editors. 2014. Chap 3, pp 53-105. DOI: 10.1002/9781118914458.ch3

Appendix 2: Properties of some common fillers [128,129].

\begin{tabular}{|c|c|c|c|c|c|c|c|}
\hline & filler & density & $\begin{array}{l}\text { modulus } \\
\text { (GPa) }\end{array}$ & $\begin{array}{c}\text { thermal } \\
\text { conductivity } \\
\left(\mathrm{W} \mathrm{m}^{-1} \mathrm{~K}^{-1}\right)\end{array}$ & $\begin{array}{c}\text { specific heat } \\
\text { capacity } \\
\left(\mathrm{J} \mathrm{kg}^{-1} \mathrm{~K}^{-1}\right)\end{array}$ & $\begin{array}{c}\text { thermal } \\
\text { expansion } \\
\left(\mathbf{K}^{-1}\right)\end{array}$ & $\begin{array}{l}\text { resistivity } \\
(\Omega \mathrm{cm})\end{array}$ \\
\hline \multirow{9}{*}{$\begin{array}{c}\text { cubic and } \\
\text { spheroidal } \\
\text { fillers }\end{array}$} & $\mathrm{CaCO}_{3}$ & 2.7 & 35 & 2.5 & 866.5 & $10^{-5}$ & $10^{10}$ \\
\hline & Dolomite & 2.87 & 35 & 2.7 & 840 & $10^{-5}$ & $5.10^{9}$ \\
\hline & $\mathrm{MgCO}_{3}$ & 3 & 35 & 2.2 & 820 & $10^{-5}$ & $5.10^{9}$ \\
\hline & $\mathrm{BaSO}_{4}$ & $4-4.5$ & 30 & 2.5 & 460 & $10^{-5}$ & - \\
\hline & Glass beads & 2.3 & 60 & 0.7 & 1130 & $8.6 .10^{-6}$ & $10^{12}-10^{16}$ \\
\hline & $\mathrm{SiO}_{2}$ & 2.2 & - & 0.015 & 794 & $5.10^{-7}$ & $10^{13}$ \\
\hline & $\mathrm{Al}(\mathrm{OH})_{3}$ & 2.6 & 30 & 2.9 & 878 & $6.5 .10^{-6}$ & $10^{10}$ \\
\hline & Carbon Black & $1.7-1.9$ & - & 2.5 & 866 & $5-11.10^{-5}$ & $10^{-1}-10^{2}$ \\
\hline & Wood Flour & $0.4-1.35$ & 10 & 0.25 & 1750 & $5.10^{-5}$ & - \\
\hline \multirow{4}{*}{$\begin{array}{l}\text { platy } \\
\text { fillers }\end{array}$} & Talc & 2.75 & 20 & 2.1 & 869.4 & $8.10^{-6}$ & $8.10^{-6}$ \\
\hline & Mica & $2.75-3.2$ & 17.2 & 2.5 & 878 & $2.5 .10^{-5}$ & $2.5 \cdot 10^{-5}$ \\
\hline & Kaolin - Clays & $2.5-2.6$ & $20-200$ & $1.96-2.1$ & $936-920$ & $3.10^{-6}-4.5 \cdot 10^{-1}$ & $8.10^{-6}-4.5 .10^{-6}$ \\
\hline & Graphite & $2-2.25$ & - & 200 & - & - & $800-2500$ \\
\hline \multirow{13}{*}{$\begin{array}{l}\text { acicular } \\
\text { and } \\
\text { fibrous } \\
\text { fillers }\end{array}$} & Wollastonite & $2.8-2.9$ & 30 & $\begin{array}{c}2.51 \\
\text { Glass fibers }\end{array}$ & 1003 & $6.5 .10^{-6}$ & - \\
\hline & A glass & 2.46 & 74 & 0.7 & 1130 & $8.5 .10^{-6}$ & $10^{12}-10^{16}$ \\
\hline & E glass & 2.59 & 73 & 0.7 & 1130 & $5.10^{-6}$ & $10^{10}-10^{17}$ \\
\hline & $\mathrm{S}$ glass & 2.48 & 85.5 & 0.7 & 1130 & $5.9 .10^{-6}$ & $10^{10}-10^{16}$ \\
\hline & & & & Aramid fibers & & & \\
\hline & Low Modulus & 1.45 & 80 & 0.05 & 1420 & $(-3.5) \cdot 10^{-6}$ & - \\
\hline & High Modulus & 1.45 & 120 & 0.05 & 1420 & $(-3 \cdot 5) \cdot 10^{-6}$ & - \\
\hline & UltraHigh Modulus & 1.47 & 180 & 0.05 & 1420 & $(-3.5) \cdot 10^{-6}$ & - \\
\hline & & & & Carbon fibers & & & \\
\hline & Low Modulus & 1.78 & 240 & 17 & 710 & -0.1 & $1.5 .10^{-3}$ \\
\hline & Intermediate Modulus & $1.76-1.80$ & 325 & 17 & 710 & -0.1 & $1.5 .10^{-3}$ \\
\hline & High Modulus & $1.79-1.90$ & 400 & 17 & 710 & -0.5 & $0.9 .10^{-3}$ \\
\hline & UltraHigh Modulus & $1.90-2.0$ & 450 & 17 & - & - & - \\
\hline
\end{tabular}


E Richaud . Polyoxymethylene Additives. In: "Polyoxymethylene Handbook: Structure, Properties, Applications and Their Nanocomposites”. Sigrid Lüftl, Visakh P.M., Sarath Chandran, editors. 2014. Chap 3, pp 53-105. DOI: 10.1002/9781118914458.ch3 REFERENCES

1. R. Pfaendner. How will additives shape the future of plastics? Polymer Degradation and Stability 91(9), 2006, p. 2249-2256.

2. J. Pospíšil. Mechanistic action of phenolic antioxidants in polymers-A review. Polymer Degradation and Stability 20(3-4), 1988, p. 181-202.

3. J. Shi, B. Jing, X. Zou, H. Luo, W. Dai. Investigation on thermo-stabilization effect and nonisothermal degradation kinetics of the new compound additives on polyoxymethylene. Journal of Materials Science 44(5), 2009, p. 1251-1257.

4. Additives for Polymers, Volume 1996, Issue 5, May 1996, Pages 3-5

5. V.M. Archodoulaki, S. Lüftl, S. Seidler. Oxidation induction time studies on the thermal degradation behaviour of polyoxymethylene. Polymer Testing 25(1), 2006, p. 83-90.

6. V.M. Archodoulaki, S. Lüftl, S. Seidler. Thermal degradation behaviour of poly(oxymethylene): 1 . Degradation and stabilizer consumption. Polymer Degradation and Stability 86(1), 2004, p. 75-83.

7. F.R. Stohler, K. Berger. Stabilization of polyacetals. Die Angewandte Makromolekulare Chemie 176(1), $1990,323-332$.

8. E. Richaud, C. Monchy-Leroy, X. Colin, L. Audouin, J. Verdu. Kinetic modelling of stabilization coupled with stabilizer loss by evaporation. Case of dithioester stabilized polyethylene. Polymer Degradation and Stability 94(11), 2009, p. 2004-2014.

9. K. Schwarzenbach, B. Gilg, Müller, G. Knobloch, J.-R. Pauquet, P. Rota-Graziosi, A. Schmitter, J. Zingg, E. Kramer. Plastics Additives Handbook. 5th Ed. by H. Zweifel. Munich, Hanser Publications, 2001. ISBN: 156990-144-9. Chap. 1. Antioxidants. p. 1-137.

10. J. Malík, G. Ligner, L. Ávár. Polymer bound HALS — expectations and possibilities. Polymer Degradation and Stability 60(1), 1998, p 205-213.

11. P.D. Calvert, N.C. Billingham. Loss of additives from polymers: A theoretical model. Journal of Applied Polymer Science 24(2), 1979, p. 357-370.

12. D. Park, D. Kobayashi, H. Suh, Y. Cho, A. Lee. Synthesis of (3-tert-butyl-4-hydroxy-5-methylphenyl) propionate derivatives and their thermal antioxidation behavior for POM. Journal of Applied Polymer Science 124(2), 2012, p. 1731-1736.

13. V.V. Gur'yanova, M.B. Neiman, B.M. Kovarskaya, V.B. Miller, G.V. Maksimova. The mechanism of the inhibited oxidation of polyformaldehyde. Polymer Science U.S.S.R. 9(10), 1967, p. 2447-2457.

14. M. Bastard. Etude de la durabilité de pièces thermoplastiques. Application au polyoxyméthylène.

Thèse ENSAM de Paris (2006).

15. E. Richaud, B. Fayolle, J. Verdu. Polypropylene stabilization by hindered phenols - Kinetic aspects. Polymer Degradation and Stability 96(1), 2011, p. 1-11.

16. Y. Hu, L. Ye, X. Zhao. Synthesis of the melamine-formaldehyde polycondensate and its thermal stabilization effect on polyoxymethylene. Polymer 47(8), 2006, p. 2649-2659.

17. V.R. Alishoyev, M.B. Neiman, B.M. Kovarskaya, V.V. Guryanova. Thermal-oxidative degradation and stabilization of polyformaldehyde. Polymer Science U.S.S.R. 4(6), 1963, p 1340-1346.

18. J. Shi, B. Jing, X. Zou, H. Luo, W. Dai. Investigation on thermo-stabilization effect and nonisothermal degradation kinetics of the new compound additives on polyoxymethylene. Journal of Materials Science 44(5), 2009, p. 1251-1257. 
E Richaud . Polyoxymethylene Additives. In: "Polyoxymethylene Handbook: Structure, Properties, Applications and Their Nanocomposites”. Sigrid Lüftl, Visakh P.M., Sarath Chandran, editors. 2014. Chap 3, pp 53-105. DOI: 10.1002/9781118914458.ch3

19. POM with improved slip. Additives for Polymers 1997(7), 1997, p 4.

20. S. Illescas, M. Sánchez-Soto, H. Milliman, D.A. Schiraldi, A. Arostegui. The morphology and properties of melt-mixed polyoxymethylene/ monosilanolisobutyl-POSS composites. High Performance Polymers 23(6), 2011, p. 457-467.

21. A. Moustaghfir, E. Tomasella, M. Jacquet, A. Rivaton, B. Mailhot, J.L. Gardette, E. Bêche. ZnO/A12O3 coatings for the photoprotection of polycarbonate. Thin Solid Films 515(2), 2006, p 662-665.

22. J.C. Crawford. 2(2-hydroxyphenyl)2H-benzotriazole ultraviolet stabilizers. Progress in Polymer Science 24(1), 1999, p. 7-43.

23. Additives for Polymers 1995(3), 1995, p. 8-9

24. F. Gugumus. Plastics Additives Handbook. 5th Ed. by H. Zweifel. Munich, Hanser Publications, 2001. ISBN: 1-56990-144-9. Chap. 2. Light Stabilizers. p. 139-423.

25. G. Wu, F. Yang, S. Zhang, X. Ren. Synthesis of an acrylate elastomer with UV stabilization and its application in polyoxymethylene. Journal of Applied Polymer Science 123(5), 2012, p. 2609-2615.

26. D. Zhou, B. You, G. Wu, X. Ren. Mechanical properties and surface morphology of photodegraded polyoxymethylene modified by a core-shell acrylate elastomer with UV stabilization. Polymer International 61(6), 2012, p 971-981.

27. E.T. Denisov. Mechanism of regeneration of hindered nitroxyl and aromatic amines. Polymer Degradation and Stability 25(2-4), 1989, p. 209-215.

28. J. Sedlář, A. Zaharadníčková. HALS - the mechanistic aspects of their action, in: A.V. Patsis (Ed.), Advances in the Stabilization and Controlled Degradation of Polymers, vol. 1, Technomic Publ. Co., Lancaster, 1989, p. 227 .

29. D. Vaillant, J. Lacoste, J. Lemaire. Stabilization of isotactic polypropylene. Problems bound to the interactions of stabilizers with pigments and fillers. Journal of Applied Polymer Science 65(3), 1997, p. 609615.

30. C. Sinturel, J. Lemaire, J.-Luc Gardette. Photooxidation of fire retarded polypropylene: III. Mechanism of HAS inactivation. European Polymer Journal 36(7), 2000, p. 1431-1443.

31. K. Antoš, J. Sedlář. Influence of brominated flame retardant thermal decomposition products on HALS. Polymer Degradation and Stability 90(1), 2005, p. 188-194.

32. N.S. Allen. Catalytic thermal oxidation of phenolic antioxidants by hindered piperidine compounds. Polymer Degradation and Stability 3(1), 1980, p. 73-81.

33. P. Carloni, L. Greci, P. Stipa, C. Rizzoli, P. Sgarabotto, F. Ugozzoli. Antioxidants and light stabilizers. Part 1. Reactions of an indolinone nitroxide and phenoxy radicals. X-ray crystallographic analysis of 1-[O-(3,5-ditert-butyl-4-hydroxy)-benzyl]-1,2-dihydro-2-methyl-2-phenyl-3-oxo-3H-indole and 3,5,3'5' -tetra-tertbutylstilbene-4,4'-quinone. Polymer Degradation and Stability 39(1), 1993, p. 73-83.

34. J. Pospíšil, S. Nešpůrek. Chain-breaking stabilizers in polymers: the current status. Polymer Degradation and Stability 49(1), 1995, p. 99-110.

35. X. Gao, C. Qu, Q. Zhang, Y. Peng, Q. Fu. Brittle-Ductile Transition and Toughening Mechanism in POM/TPU/CaCO3 Ternary Composites. Macromolecular Materials and Engineering 289(1), 2004, p. 41-48.

36. S. Wu. Phase structure and adhesion in polymer blends: A criterion for rubber toughening. Polymer 26(2), 1985, p. 1855-1863. 
E Richaud . Polyoxymethylene Additives. In: "Polyoxymethylene Handbook: Structure, Properties, Applications and Their Nanocomposites”. Sigrid Lüftl, Visakh P.M., Sarath Chandran, editors. 2014. Chap 3, pp 53-105. DOI: 10.1002/9781118914458.ch3

37. H. Kanai, V. Sullivan, A. Auerbach. Impact modification of engineering thermoplastics. Journal of Applied Polymer Science 53(5), 1994, p. 527-541.

38. J. Horrion, S. Cartasegna, P.K. Agarwal. Morphology, thermal, and mechanical properties of polyacetal/ionomer blends. Polymer Engineering \& Science 36(16), 1996, p. 2061-2068.

39. X. Wang, X. Cui. Effect of ionomers on mechanical properties, morphology, and rheology of polyoxymethylene and its blends with methyl methacrylate-styrene-butadiene copolymer. European Polymer Journal 41(4), 2005, p. 871-880.

40. X. Zhao, L. Ye. Structure and mechanical properties of polyoxymethylene/multi-walled carbon nanotube composites. Composites Part B: Engineering 42(4), 2011, p. 926-933.

41. M. Mehrabzadeh, D. Rezaie. Impact modification of polyacetal by thermoplastic elastomer polyurethane Journal of Applied Polymer Science 84(14), 2002, p. 2573-2582.

42. R. Nalini Uthaman, A. Pandurangan and S.S.M. Abdul Majeed. Mechanical, thermal, and morphological characteristics of compatibilized and dynamically vulcanized polyoxymethylene/ethylene propylene diene terpolymer blends. Polymer Engineering \& Science 47(6), 2007, p. 934-942.

43. S. Hashemi, M.T. Gilbride, J. Hodgkinson. Mechanical property relationships in glass-filled polyoxymethylene. Journal of Materials Science 31(19), 1996, p. 5017-5025.

44. X. Hu, L. Jiang. Preparation and characterisation of oil-containing POM/PU blends. Journal of Synthetic Lubrication 15(1), 1998, p. 19-29.

45. J. Kurja, N.A. Mehl. Plastics Additives Handbook. 5th Ed. by H. Zweifel. Munich, Hanser Publications, 2001. ISBN: 1-56990-144-9. Chap. 18. Nucleating Agents for Semi-crystalline Polymers. p. 967-989.

46. A. Lazzeri, A. Marchetti and G. Levita. Fatigue and fracture in polyacetal resins. Fatigue \& Fracture of Engineering Materials \& Structures 20(8), 1997, p. 1207-1216.

47. W. Hao, W. Yang, H. Cai, Y. Huang. Non-isothermal crystallization kinetics of polypropylene/silicon nitride nanocomposites. Polymer Testing 29(4), 2010, p. 527-533.

48. P. Zou, S. Tang, Z. Fu, H. Xiong. Isothermal and non-isothermal crystallization kinetics of modified rape straw flour/high-density polyethylene composites. International Journal of Thermal Sciences 48(4), 2009, p. 837846.

49. Q. Ding, W.-L. Dai, P. Zhang. The effect of polyvinylidene fluoride on nonisothermal crystallization behavior of polyoxymethylene. Polymer Engineering \& Science 47(12), 2007, p. 2034-2040.

50. T. Sun, Y. Lai, L. Ye, X. Zhao. A new and highly efficient formaldehyde absorbent of polyoxymethylene. Polymer for Advanced Technololgy 19(9), 2008, p. 1286-1295.

51. W. Xu, P. He. Isothermal crystallization behavior of polyoxymethylene with and without nucleating agents. Journal of Applied Polymer Science 80(2), 2001, p. 304-310.

52. Y. Hu, L. Ye. Nucleation effect of polyamide on polyoxymethylene. Polymer Engineering \& Science 45(8), 2005, p. 1174-1179.

53. Y. Zeng, P. Liu, J. Du, L. Zhao, P.M. Ajayan, H.-M. Cheng. Increasing the electrical conductivity of carbon nanotube/polymer composites by using weak nanotube-polymer interactions. Carbon 48(12), 2010, p. 35513558 .

54. N. Yu, L. He, Y. Ren, Q. Xu. High-crystallization polyoxymethylene modification on carbon nanotubes with assistance of supercritical carbon dioxide: Molecular interactions and their thermal stability. Polymer 52(2), 2011, p. 472-480. 
E Richaud . Polyoxymethylene Additives. In: "Polyoxymethylene Handbook: Structure, Properties, Applications and Their Nanocomposites”. Sigrid Lüftl, Visakh P.M., Sarath Chandran, editors. 2014. Chap 3, pp 53-105. DOI: 10.1002/9781118914458.ch3

55. Y. Shu, L. Ye, X. Zhao. High Efficiency Nucleating Agents of Polyoxymethylene. Polymer-Plastics Technology and Engineering 45(8), 2006, p. 963-970.

56. S. Siengchin, P. Sinpayakun, S. Suttiruengwong, U. Asawapirom. Effect of nanofiller aspect ratio on the stress relaxation and creep response of toughened POM composites. Mechanics of Composite Materials 46(3), 2010, p. 341-348.

57. R. Scherrer, R.L. Sykes. Plastics Additives Handbook. 5th Ed. by H. Zweifel. Munich, Hanser Publications, 2001. ISBN: 1-56990-144-9. Chap. 15. Colorants. p. 831-899.

58. P.P. Klemchuk Influence of pigments on the light stability of polymers: A critical review. Polymer Photochemistry 3(1), 1983, p. 1-27.

59. R.E. Day. The role of titanium dioxide pigments in the degradation and stabilisation of polymers in the plastics industry. Polymer Degradation and Stability 29(1), 1990, p. 73-92.

60. M. Edge, C.M. Liauw, N.S. Allen, R. Herrero. Surface pinking in titanium dioxide/lead stabiliser filled PVC profiles. Polymer Degradation and Stability 95(10), 2010, p. 2022-2040.

61. U. Gesenhues. Influence of titanium dioxide pigments on the photodegradation of poly(vinyl chloride) Polymer Degradation and Stability 68(2), 2000, p. 185-196.

62. J.M. Peña, N.S. Allen, M. Edge, C.M. Liauw, B. Valange. Interactions between carbon black and stabilisers in LDPE thermal oxidation. Polymer Degradation and Stability 72(1), 2001, p. 163-174.

63. J. Fock. On the influence of carbon black on the thermal degradation of polytetrafluoroethylene. Journal of Polymer Science Part B: Polymer Letters 6(2), 1968, p. 127-131.

64. J. Mwila, M. Miraftab, A.R. Horrocks. Effect of carbon black on the oxidation of polyolefins-An overview Polymer Degradation and Stability 44(3), 1994, p. 351-356.

65. J.M. Peña, N.S. Allen, M. Edge, C.M. Liauw, F. Santamaría, O. Noiset, B. Valange. Factors affecting the adsorption of stabilisers on to carbon black (flow micro-calorimetry and FTIR studies): Part I primary phenolic antioxidants. Journal of Materials Science 36(12), 2001, p. 2885-2898.

66. J.H. Troitzsch. International plastics flammability handbook: principles, regulations, testing and approval. 2nd ed. Munich, Germany: Hanser Publishers; 1990.

67. C.P. Fenimore, F.J. Martin. Flammability of polymers. Combustion and Flame 10(2), 1966, p. 135-139.

68. J.L. Isaacs. Oxygen index flammability test. Journal of Fire and Flammability 1, 1970, p. 36-47.

69. L.G. Imhof, K.C. Stueben. Evaluation of the smoke and flammability characteristics of polymer systems Polymer Engineering \& Science 13(2), 1973, p. 146-152.

70. G.C. Tesoro. Chemical modification of polymers with flame-retardant compounds. Journal of Polymer Science: Macromolecular Reviews 13(1), 1978, p. 283-353.

71. T.R. Hull, A. Witkowski, L. Hollingbery. Fire retardant action of mineral fillers. Polymer Degradation and Stability 96(8), 2011, 1462-1469.

72. P. Kiliaris, C.D. Papaspyrides. Polymer/layered silicate (clay) nanocomposites: An overview of flame retardancy. Progress in Polymer Science 35(7), 2010, p. 902-958.

73. Y. Liu, Z. Wang, Q. Wang. Effects of Magnesium Hydroxide and Its Synergistic Systems on the Flame Retardance of Polyformaldehyde. Journal of Applied Polymer Science 125(2), 2012, p. 968-974. 
E Richaud . Polyoxymethylene Additives. In: "Polyoxymethylene Handbook: Structure, Properties, Applications and Their Nanocomposites”. Sigrid Lüftl, Visakh P.M., Sarath Chandran, editors. 2014. Chap 3, pp 53-105. DOI: 10.1002/9781118914458.ch3

74. Z.-Y. Wang, Y. Liu, Q. Wang .Flame retardant polyoxymethylene with aluminium hydroxide/melamine/novolac resin synergistic system. Polymer Degradation and Stability 95(6), 2010, p. 945954.

75. S. Sun, Y. He, X. Wang, D. Wu. Flammability characteristics and performance of halogen-free flameretarded polyoxymethylene based on phosphorus-nitrogen synergistic effects. Journal of Applied Polymer Science 118(1), 2010, p. 611-622.

76. H. Harashina, Y. Tajima, T. Itoh. Synergistic effect of red phosphorus, novolac and melamine ternary combination on flame retardancy of poly(oxymethylene). Polymer Degradation and Stability 91(9), 2006, p.1996-2002.

77. Q. Zhang, Y. Chen. Synergistic effects of ammonium polyphosphate/melamine intumescent system with macromolecular char former in flame-retarding polyoxymethylene Journal of Polymer Research 18(2), 2011, 293-303,

78. F. Wylin. Plastics Additives Handbook. 5th Ed. by H. Zweifel. Munich, Hanser Publications, 2001. ISBN: 156990-144-9. Chap 10. Antistatic additives. p. 655-673.

79. E. Richter. Plastics Additives Handbook. 5th Ed. by H. Zweifel. Munich, Hanser Publications, 2001. ISBN: 1-56990-144-9. Lubricants. p. 539-579.

80. Clariant opens new production line for micronized waxes. Additives for Polymers 2002(12), 2002, p. 5.

81. http://www.axelplastics.com/pdffolder/datasheets/TD\%20INT-35UDH.pdf

82. R.L. Merker, M.J. Scott. The einstein viscosity-concentration relationship - application to true solutions of the large spherical molecule tetrakis (trimethylsilyl)methane. Journal of Colloid Science 19(3), 1964, p. 245-251.

83 T. Hanemann. Influence of particle properties on the viscosity of polymer-alumina composites. Ceramics International 34(8), 2008, p. 2099-2105.

84. T. Hanemann. Viscosity change of unsaturated polyester-alumina-composites using polyethylene glycol alkyl ether based dispersants. Composites Part A: Applied Science and Manufacturing 37(11), 2006, p. $2155-$ 2163.

85. N.L Hancox. Thermal effects on polymer matrix composites: Part 1. Thermal cycling. Materials \& Design 19(3), 1998, p. 85-91.

86. J. He, L. Zhang, C. Li. Thermal conductivity and tribological properties of POM-Cu composites. Polymer Engineering and Science 50(11), 2010, p. 2153-2159.

87. K. Kawaguchi, K. Mizuguchi, K. Suzuki, H. Sakamoto, T. Oguni. Mechanical and physical characteristics of cellulose-fiber-filled polyacetal composites. Journal of Applied Polymer Science 118(4), 2010, p. 1910-1920.

88. X. Zhao, L.Ye. Study on the thermal conductive polyoxymethylene/graphite composites. Journal of Applied Polymer Science 111(2), 2009, p. 759-767.

89. X. Zhao, L. Ye. Preparation, structure, and property of polyoxymethylene/carbon nanotubes thermal conducive composites. Journal of Polymer Science Part B: Polymer Physics 48(8), 2010, p. 905-912.

90. D. Kumlutaş, İ.H. Tavman, M. Turhan Çoban. Thermal conductivity of particle filled polyethylene composite materials. Composites Science and Technology 63(1), 2003, p 113-117.

91 H.W. Russell. Principles of heat flow in porous ceramics. Journal of the American Ceramic Society 18(1-12), 1935, p. 1-5.

92. H. Hatta, M. Taya. Effective thermal conductivity of a misoriented short fiber composite. Journal of Applied Physics 58(7), 1985, p. 2478-2486. 
E Richaud . Polyoxymethylene Additives. In: "Polyoxymethylene Handbook: Structure, Properties, Applications and Their Nanocomposites". Sigrid Lüftl, Visakh P.M., Sarath Chandran, editors. 2014. Chap 3, pp 53-105. DOI: 10.1002/9781118914458.ch3

93. A. Boudenne, S. Khaldi Temperature and liquid crystal concentration effect on thermal conductivity of poly(styrene) dispersed 5CB liquid crystal. Journal of Applied Polymer Science 89(2), 2003, p. 481-486.

94. Y. Agari, M. Tanaka, S. Nagai, T. Uno Thermal conductivity of a polymer composite filled with mixtures of particles. Journal of Applied Polymer Science 34(4), 1987, p. 1429-1437.

95. X. Zhao, L. Ye. Study on the thermal conductive polyoxymethylene/graphite composites. Journal of Applied Polymer Science 111(2), 2009, p. 759-767.

96. N. Ning, S. Fu, W. Zhang, F. Chen, K. Wang, H. Deng, Q. Zhang, Q. Fu. Realizing the enhancement of interfacial interaction in semicrystalline polymer/filler composites via interfacial crystallization. Progress in Polymer Science, In Press, Corrected Proof, Available online 26 December 2011

97. J.C. Halpin, J.L. Kardos. The Halpin-Tsai Equations: A Review. Polymer Engineering and Science 16(5), 1976, p 344-352.

98 http://www.rtpcompany.com/info/data/0800/index.htm

99. K. Kawaguchi, K. Mizuguchi, K. Suzuki, H. Sakamoto, T. Oguni. Mechanical and physical characteristics of cellulose-fiber-filled polyacetal composites. Journal of Applied Polymer Science 118(4), 2010, p. 1910-1920.

100. S. Wacharawichanant, S. Thongyai, A. Phutthaphan, C. Eiamsam-ang. Effect of particle sizes of zinc oxide on mechanical, thermal and morphological properties of polyoxymethylene/zinc oxide nanocomposites. Polymer Testing 27(8), 2008, p 971-976.

101. Y.F. Fu, K. Hu, J. Li, Z.H.Y. Sun and F.Q. Zhang, et al. Influence of nano-SiO2 and carbon fibers on the mechanical properties of POM composites. Mechanics of Composite Materials 47(6), 2011, 659-662.

102. A. James Jose, M. Alagar. Development and characterization of organoclay-filled polyoxymethylene nanocomposites for high performance applications. Polymer Composites 32(9), 2011, p. 1315-1324.

103. P.I. Bashtannik, A.I., Kabak, O.V. Chervakov. Study of the effect of the dressing of carbon fibers on the properties of carbon-fiber-reinforced plastics based on polyacetals. Mechanics of Composite Materials 33(1), 1997, p. 64-69.

104. S. Siengchin, P. Sinpayakun, S. Suttiruengwong, U. Asawapirom, Effect of nanofiller aspect ratio on the stress relaxation and creep response of toughened POM composites. Mechanics of Composite Materials 46(3), 2010, p. 341-348.

105. L. Yu, S. Yang, H. Wang, Q. Xue. An investigation of the friction and wear behaviors of micrometer copper particle- and nanometer copper particle-filled polyoxymethylene composites. Journal of Applied Polymer Science 77(11), 2000, p. 2404-2410.

106. Y.P. Mamunya, Y.V. Muzychenko, P. Pissis, E.V. Lebedev, M.I. Shut. Percolation phenomena in polymers containing dispersed iron. Polymer Engineering \& Science 42(1), 2002, p. 90-100.

107. H. Yin, H. Bao, J. Li, Z. Guo, J. Yu. Electrical properties of multiwalled carbon nanotube/carbon black hybrid filler filled polyoxymethylene composites. Acta Polymerica Sinica 9, 201, p. 1152-1156.

108. Y. Zeng, Z. Ying, J. Du, H.-M. Cheng. Effects of Carbon Nanotubes on Processing Stability of Polyoxymethylene in Melt-Mixing Process. Journal of Physical Chemistry C 111, 2007, p. 13945-13950.

109. S. Odi-Owei, D.J. Schipper. Tribological behaviour of unfilled and composite polyoxymethylene. Wear 148(2), 1991, p. 363-376.

110. H. Benabdallah. Friction and wear of blended polyoxymethylene sliding against coated steel plates. Wear 254(12), 2003, p. 1239-1246. 
E Richaud . Polyoxymethylene Additives. In: "Polyoxymethylene Handbook: Structure, Properties, Applications and Their Nanocomposites". Sigrid Lüftl, Visakh P.M., Sarath Chandran, editors. 2014. Chap 3, pp 53-105. DOI: 10.1002/9781118914458.ch3

111. Y. Gao, S. Sun, Y. He, X. Wang, D. Wu. Effect of poly(ethylene oxide) on tribological performance and impact fracture behavior of polyoxymethylene/polytetrafluoroethylene fiber composites. Composites Part B: Engineering 42(7), 2011, p. 1945-1955.

112. POM compound with low friction. Additives for Polymers 1997(9), 1997, p. 3.

113. How best to lubricate plastics: internal or external? - or is it so new? Additives for Polymers 1998(1), 1998, p. 9-10.

114. C.-Y. Huang, W.-Y. Chiang. Synergistic effect of PTFE and sodium etched PTFE on polyacetal ternary blends. European Polymer Journal 29(6), 1993, p. 843-849.

115. L.-H. Sun, Z.-G. Yang, X.-H. Li. Study on the friction and wear behavior of POM/A12O3 nanocomposites. Wear 264(7-8), 2008, p. 693-700.

116. K.H. Hu, J. Wang, S. Schraube, Y.F. Xu, X.G. Hu, R. Stengler. Tribological properties of MoS2 nano-balls as filler in polyoxymethylene-based composite layer of three-layer self-lubrication bearing materials. Wear 266(11-12), 2009, p. 1198-1207.

117. POM with improved slip. Additives for Polymers 1997(7), 1997, p. 4.

118. V. Compañ, L.F. Del Castillo, S.I. Hernández, M. Mar López-González, E. Riande. Crystallinity effect on the gas transport in semicrystalline coextruded films based on linear low density polyethylene. Journal of Polymer Science, Part B: Polymer Physics 48(6), 2010, p. 634-642

119. A.S. Michaels, H.J. Bixler. Flow of gases through polyethylene. Journal of Polymer Science 50, 1961 , p. 413-439.

120. M. Hedenqvist, U.W. Gedde. Diffusion of small-molecule penetrants in semicrystalline polymers. Progress in Polymer Science 21, 1996, p 299-333.

121. R.B. Jenkins, G.S. Park. The effect of micro-structure on the diffusion of n-hexadecane and ddt in poly(1,4butadienes). Journal of Membrane Science 15, 1983, p. 127-140.

122. G.G. Gutiérrez. Oxydation des Nanocomposites à Matrice Polyoléfinique. Thèse Art et Metiers ParisTech (2010).

123. T. Kongkhlang, Y. Kousaka, T. Umemura, D. Nakaya, W. Thuamthong, Y. Pattamamongkolchai, S. Chirachanchai. Role of primary amine in polyoxymethylene (POM)/bentonite nanocomposite formation. Polymer 49(6), 2008, p. 1676-1684.

124. Dow Corning to launch silicone additives worldwide. Additives for Polymers 1996(11), 1996, p. 2.

125. X. Hu, L. Jiang. Preparation and characterisation of oil-containing POM/PU blends. Journal of Synthetic Lubrication 15(1), 1998, p. 19-29.

126. P.W. Dufton. Functional Additives for the Plastics Industry: Trends in Use. Smithers Rapra Publishing, 1 juil. 1998 - 284 pages.

127. J. Shi, B. Jing, X. Zou, H. Luo, W. Dai. Investigation on thermo-stabilization effect and nonisothermal degradation kinetics of the new compound additives on polyoxymethylene. Journal of Materials Science 44(5), 2009, p.1251-1257. DOI: 10.1007/s10853-008-3227-4.

128. W. Hohenberger. Plastics Additives Handbook. 5th Ed. by H. Zweifel. Munich, Hanser Publications, 2001. ISBN: 1-56990-144-9. Fillers and Reinforcements/Coupling Agents. Chap. 17. p. 919-969.

129. R. Sengupta, M. Bhattacharya, S. Bandyopadhyay, A.K. Bhowmick. A review on the mechanical and electrical properties of graphite and modified graphite-reinforced polymer composites. Progress in Polymer Science 36(5), 2011, p. 638-670. 